\title{
Preparation of Nanostructured Microporous Metal Foams through Flow Induced Electroless Deposition
}

\author{
Galip Akay ${ }^{1,2,3}$ and Burak Calkan ${ }^{1,4}$ \\ ${ }^{1}$ School of Chemical Engineering and Advanced Materials, Newcastle University, Newcastle upon Tyne NE1 7RU, UK \\ ${ }^{2}$ Canik Başarı University, Canik, 55080 Samsun, Turkey \\ ${ }^{3}$ GAP Technologies, 1 Grosvenor Place, 8th Floor, London SW1X 7HU, UK \\ ${ }^{4}$ Optimum, Domodedovskiy Rayon, Starosyanova Village, Sadovaya Street No. 4, Moscow 142030, Russia
}

Correspondence should be addressed to Galip Akay; galip.akayl@gmail.com

Received 15 May 2015; Revised 20 June 2015; Accepted 12 July 2015

Academic Editor: Ovidiu Ersen

Copyright (C) 2015 G. Akay and B. Calkan. This is an open access article distributed under the Creative Commons Attribution License, which permits unrestricted use, distribution, and reproduction in any medium, provided the original work is properly cited.

\begin{abstract}
Monolithic nanostructured metallic porous structures with a hierarchy of pore size ranging from ca. $10 \mu \mathrm{m}$ to $1 \mathrm{~nm}$ are processed for use as microreactors. The technique is based on flow induced electroless deposition of metals on a porous template known as PolyHIPE Polymer. The process is conducted in a purpose built flow reactor using a processing protocol to allow uniform and efficient metal deposition under flow. Nickel chloride and sodium hypophosphite were used as the metal and reducing agent, respectively. Electroless deposition occurs in the form of grains with a composition of $\mathrm{Ni}_{x} \mathrm{P}_{y}$ in which the grain size range was ca. 20-0.2 $\mu \mathrm{m}$ depending on the composition of the metal deposition solution. Structure formation in the monoliths starts with heat treatment above $600^{\circ} \mathrm{C}$ resulting in the formation of a 3-dimensional network of capillary-like porous structures which form the walls of large arterial pores. These monoliths have a dense but porous surface providing mechanical strength for the monolith. The porous capillary-like arterial pore walls provide a large surface area for any catalytic activity. The mechanisms of metal deposition and nanostructure formation are evaluated using scanning electron microscopy, energy dispersive X-ray analysis, XRD, BET-surface area, and mercury intrusion porosimetry.
\end{abstract}

\section{Introduction}

1.1. Structured Catalysts. Although catalysis accelerates reaction rates and chemical conversions, accessibility of the reactants to and removal of products from the catalytic sites are important to realize the full potential of catalysts. Supported catalyst systems are intended for these provisions. Catalysts are either deposited as a thin film on the walls of reactors or deposited on high surface area porous support particles and subsequently palletized for use in particulate form in packed/fluidized bed reactors or stirred tanks. These two techniques have certain drawbacks: in coated systems, catalyst adhesion can be nonuniform and weak while the accessibility of the active sites within the interior of the catalyst pallets is hindered due to low porosity, small pore size, and connectivity. Therefore, when the reactions are transport-limited, even such systems cannot provide adequate accessibility of the catalytic sites since the high surface area support materials themselves restrict transport processes.

In recent years, the so-called "structured catalysts" became available in order to address these problems. The catalyst supports are often in the form of macroporous foams or monoliths which actually form the reactor, acting as a static mixer at the same time. In order to increase the surface area of the monolithic catalyst supports without excessive pressure drop, macrochannel systems are utilized in industry such as those in catalytic converters. In these systems, not only the local hydrodynamic conditions but also the catalyst coating thickness can be controlled to obtain well-defined catalytic reactors and they invariably outperform reactors with catalyst particles in packed bed or stirred tank configuration [1-3]. Monolithic reactors combine the advantages of fixed bed (ease of handling) and turbulent stirred tank reactors (intense 
contacting) while providing a narrow residence time distribution, avoiding mal-distribution and scale-up problems.

1.2. Monolithic Reactors with Hierarchic Pore Structure. Monolithic catalyst systems with nonporous/low porosity walls also suffer from certain disadvantages, such as cost, low catalyst loading, integrity of the catalyst coating on the monolith channel walls, and the presence of two independently controlled length scales which only provide partial accessibility of the catalytic sites. The accessibility of the nanosized catalytic sites is achieved most effectively by a hierarchical channel or pore network structures which are ubiquitous in nature [4-6]. In these systems, the main chemical processes are principally controlled at the molecular/nanoscale as many of these processes are transport-limited, while the continuous supply/removal of reactants/products is achieved through capillaries/pores of ever increasing diameter. Such a system provides an optimum architecture incorporating micro-/nanoscale with chemically functional features within the macrosystem at an optimum surface area for catalytic applications. Such hierarchically structured catalyst systems with fractal-like meso- to macropore size distribution can be expected to be more efficient and robust due to the enhanced surface area and accessibility leading to the intensification of chemical processes [6].

1.3. Production of Porous Metallic Structures. There are several important applications of metallic foams as both structural/engineering and specialized materials. Excellent periodical reviews are available describing the manufacture, characterization, properties, and application of these materials [79]. One particular metallic foam is produced through electrochemical metal deposition on polyurethane foam followed by heat treatment when the template polymer is burnt off $[10,11]$. These materials are commonly used for catalyst support to obtain supported catalyst systems as well as electrode in fuel cells. These materials are marketed as Metapore, Celnet, Retimet, and Recemet. Their macrostructure is very similar to some of the materials produced by the current technique except that these materials do not have a hierarchy of pores, while their surface area density (surface area per unit volume) is some 100 -fold smaller and pore size is some 50 times smaller than those produced in this work.

\subsection{PolyHIPE Polymers as Monolithic Microreactors and as} Templates for Electroless Metal Deposition. In the design of novel monoliths with hierarchical porous catalytic reactors having a pore size range of ca. $100 \mu \mathrm{m}$ to a few nanometers, the first step is to obtain structures with controlled pore size and porosity and functionalize them to impart both nanostructure and catalytic activities. One such highly versatile monolithic (or indeed particulate) system is known as PolyHIPE Polymer (PHP) which was developed at Unilever Research Laboratory at Port Sunlight (UK) during the 1980 s by a team including one of the present authors (Galip Akay) who also developed the processing of the basic material and advanced its use in both small and large scale applications [12, 13]. A summary of PolyHIPE Polymer chemistry can be found in [14].
PolyHIPE Polymers are prepared through a high internal phase emulsion (HIPE) polymerization route and hence the acronymic name, PolyHIPE, which reflects the processing history. Depending on the composition of the HIPE, processing, and polymerization history, PHPs can have hierarchical pore and interconnects over a size range ca. $100 \mu \mathrm{m}$ to nanometre, while the pore volume can reach as high as $97 \%$ for practical applications. Chemical/biochemical functionalization processes of PHPs are relatively easy [15] and, coupled with their easy manufacture in monolithic form with welldefined macro-, meso-, and nanostructures providing a hierarchy of pores, they are ideally suited for process intensification [6] in agricultural, biological, and chemical processes, in both small scale or large scale applications. Further acceleration, efficiency and selectivity in processing are obtained when PHPs are used as monoliths.

PolyHIPE Polymers can be chemically and biologically functionalized [16-20] in order to achieve mimicking of nature's processing strategy and applied to tissue engineering, bioprocess intensification, and agroprocess intensification. Furthermore, nonbiological functionalization processes were used for specific applications such as separation processes [21], fast response ion-exchange resins [22], and environmental and energy conversion processes [23].

Monolithic chemical or biochemical reactors have several advantages over packed bed/fluidised bed or stirred tank reactors even when hierarchic catalysts are used in particulate form. In monolithic flow-through reactors, there is no channeling and the distribution of flow across the crosssection of the monolithic reactor is more uniform and the catalytic sites are only micrometers away from the reactants. Furthermore, in some reactions when the rate is limited by product concentration, flow through the monolith allows the removal of the product from the catalytic sites into the bulk/convective flow. These characteristics result in process intensification, and direct comparison of packed bed and monolithic reactor performance is available when PolyHIPE Polymer was used in particulate form (packed bed) [17] and in monolithic form [18].

As reviewed above, PolyHIPE Polymer monoliths have been used successfully for intensifying processes in agriculture, biology, chemical/physical-chemical, and energy conversion processes due to their unique hierarchic pore structure in which large arterial pores with large interconnecting holes (windows) facilitate convective mass transfer, while walls of the arterial pores provide the catalytic sites which are connected to the arterial pores via mesoscale (typically $100 \mathrm{~nm}$ ) pores [15]. However, to the best of our knowledge, there is no metallic equivalent form of such monolithic structures. Therefore, the manufacture of such metallic monoliths will increase the temperature and pressure range of chemical/physical-chemical processes and catalyst, reactant, and product ranges of these reactors.

1.5. Electroless Deposition. There are different mechanisms in the literature suggested for the chemical reduction of nickel salts by hypophosphites. Probably the most widely accepted mechanism is the one suggested by Brenner and Riddell [24] as also reported in $[25,26]$. They stated that atomic hydrogen 
is the real nickel reductant. With sufficient energy and a catalytic surface, hypophosphite ions react with water and they are oxidized to orthophosphite. The hydrogen generated by this reaction is absorbed onto the catalytic surface:

$$
\left(\mathrm{H}_{2} \mathrm{PO}_{2}\right)^{-}+\mathrm{H}_{2} \mathrm{O} \longrightarrow \mathrm{H}_{2} \mathrm{PO}_{3}^{-}+2 \mathrm{H}_{\mathrm{abs}}
$$

Nickel ions at the catalytic surface are reduced by the absorbed active hydrogen:

$$
\mathrm{Ni}^{+2}+2 \mathrm{H}_{\mathrm{abs}} \longrightarrow\left(\mathrm{Ni}^{+2}+2 \mathrm{H}^{+}+2 \mathrm{e}\right) \longrightarrow \mathrm{Ni}^{0}+2 \mathrm{H}^{+}
$$

The liberation of hydrogen gas in the catalytic nickel reduction is the result of recombination of the hydrogen atoms:

$$
2 \mathrm{H}_{\mathrm{abs}} \longrightarrow(\mathrm{H}+\mathrm{H}) \longrightarrow \mathrm{H}_{2}
$$

The mechanism of atomic hydrogen being the real nickel reductant has found support from many researchers. But still it has failed to explain certain issues like the simultaneous reduction of nickel and hydrogen. Also there is no clarification of why stoichiometric consumption of hypophosphite never exceeds $50 \%$. Usually $5 \mathrm{~kg}$ of sodium hypophosphite is required to reduce $1 \mathrm{~kg}$ of nickel for an average efficiency of $37 \%$. In another source [27], this problem was explained by the catalytic oxidation of most of the hypophosphite present to orthophosphate and gaseous hydrogen evolution according to the reaction which occurs independently of the deposition of nickel and phosphorus, hence causing the low efficiency of electroless nickel solutions:

$$
\left(\mathrm{H}_{2} \mathrm{PO}_{2}\right)^{-}+\mathrm{H}_{2} \mathrm{O} \longrightarrow \mathrm{H}^{+}+\left(\mathrm{HPO}_{3}\right)^{-2}+\mathrm{H}_{2}
$$

The most important application of electroless deposition is the coating of plastic surfaces with metal or indeed metal coating of surfaces. In these applications, coating thickness is small (a few tens of microns) and then the removal of hydrogen is simple. In the present case, metal deposition is extensive and confined to micron size pore walls. Furthermore, the walls of the porous template polymer surface were not catalyzed to achieve metal deposition and polymer/metal integration was not necessary. Nevertheless, the above chemical reactions indicate that the removal of hydrogen is of paramount importance in order to sustain metal deposition.

1.6. Novelty of the Current Process. The characteristics of flowthrough monolithic reactors have been used in this research (most importantly, the removal of reaction products) in order to obtain electroless deposition. In this study, we use PolyHIPE Polymers to electrolessly deposit metals and subsequently heat-treat the resulting constructs to obtain monoliths which can be used as gas separation and reaction media at high temperatures. Previous attempts to produce monolithic porous metal systems through electroless deposition using PolyHIPE Polymer as template failed because the processing setup did not allow the continuous removal of reaction products during deposition. Hence, only small, weak porous metallic particles could be obtained [28].

As we aim to demonstrate that catalytic microreactors with hierarchic pore structure can be produced through this method, we need to choose the composition of the metal deposition solution carefully. In this case, the introduction of phosphorous in the reactor should be avoided as phosphorus is a well-known catalyst poison [29]. Instead, a dimethylamine borane system was chosen in order to obtain monoliths with catalyst activity in which the presence of boron enhances resistance of nickel catalyst against poisoning [30]. The results with dimethylamine borane will be reported separately.

\section{Experimental Section}

2.1. Preparation of Template PolyHIPE Polymer (PHP) for Metal Deposition. PHP is conveniently prepared through the polymerization of a polymerizable continuous phase of a high internal phase water-in-oil emulsion (HIPE) using the equipment in Figure 1. The effects of temperature and the non-Newtonian fluid mechanics aspects of the HIPE formation and dispersed phase (water) droplet size reduction without phase inversion to oil-in-water have been described in [31]. The techniques used in this study ensure the preparation of macroporous polymers with well-controlled internal architecture, pore and interconnect sizes, and their distributions. The continuous (oil) phase of HIPE consisted of styrene, $78 \mathrm{wt} \%$ (monomer); divinylbenzene, $8 \mathrm{wt} \%$ (crosslinking agent); and sorbitan monooleate (Span80), 14 wt\% (surfactant), all obtained in reagent grade from Aldrich and used without any further treatment. The dispersed (aqueous) phase is comprised of double distilled water containing $1 \mathrm{wt} \%$ potassium persulfate as initiator for polymerization.

The total volume of the aqueous phase and oil phase combined was $225 \mathrm{~mL}$, which was the optimum amount for this particular mixing vessel (internal diameter was $12 \mathrm{~cm}$ ) (Figure 1). Mixing was conducted using two flat paddles (diameter $9 \mathrm{~cm}$ ) that were stacked $1 \mathrm{~cm}$ apart from each other at right angles. The bottom impeller was $0.5 \mathrm{~cm}$ above the bottom of the vessel. Rotational speed of the impellers was $300 \mathrm{rpm}$. The phase volume of the aqueous phase was $95 \%$ in order to obtain highly open pore polymer (pore sizes ca. $50-60 \mu \mathrm{m})$. Agitation of aqueous phase and oil phase was performed in the mixing vessel, which was heated by a water jacket that circulated hot water at $60^{\circ} \mathrm{C}$ by using a water bath. Prior to the mixing of the constituents, the hot water circulation was started to ensure that the reactor reached the required temperature. The aqueous phase was also preheated to $60^{\circ} \mathrm{C}$ on a hot plate. When the aqueous phase and the mixing vessel temperatures were set, all the oil phase $(11.3 \mathrm{~mL})$ was poured into the vessel at once. The mixing was conducted in a closed environment to prevent monomer/cross-linker loss through evaporation. Emulsification at relatively high temperatures results in large pores at a given mixer speed of $220 \mathrm{rpm}$ and 3 minutes mixing time.

Feeding of the aqueous phase $(214 \mathrm{~mL})$ was performed by four tubes connected to two peristaltic pumps. The rate of pumping was adjusted at such a speed that all the aqueous phase was dosed into the vessel in 2 minutes. The impeller was started at the same time as the dosing of the aqueous phase into the vessel. After dosing all the aqueous phase into the oil phase, the mixture was stirred for another 


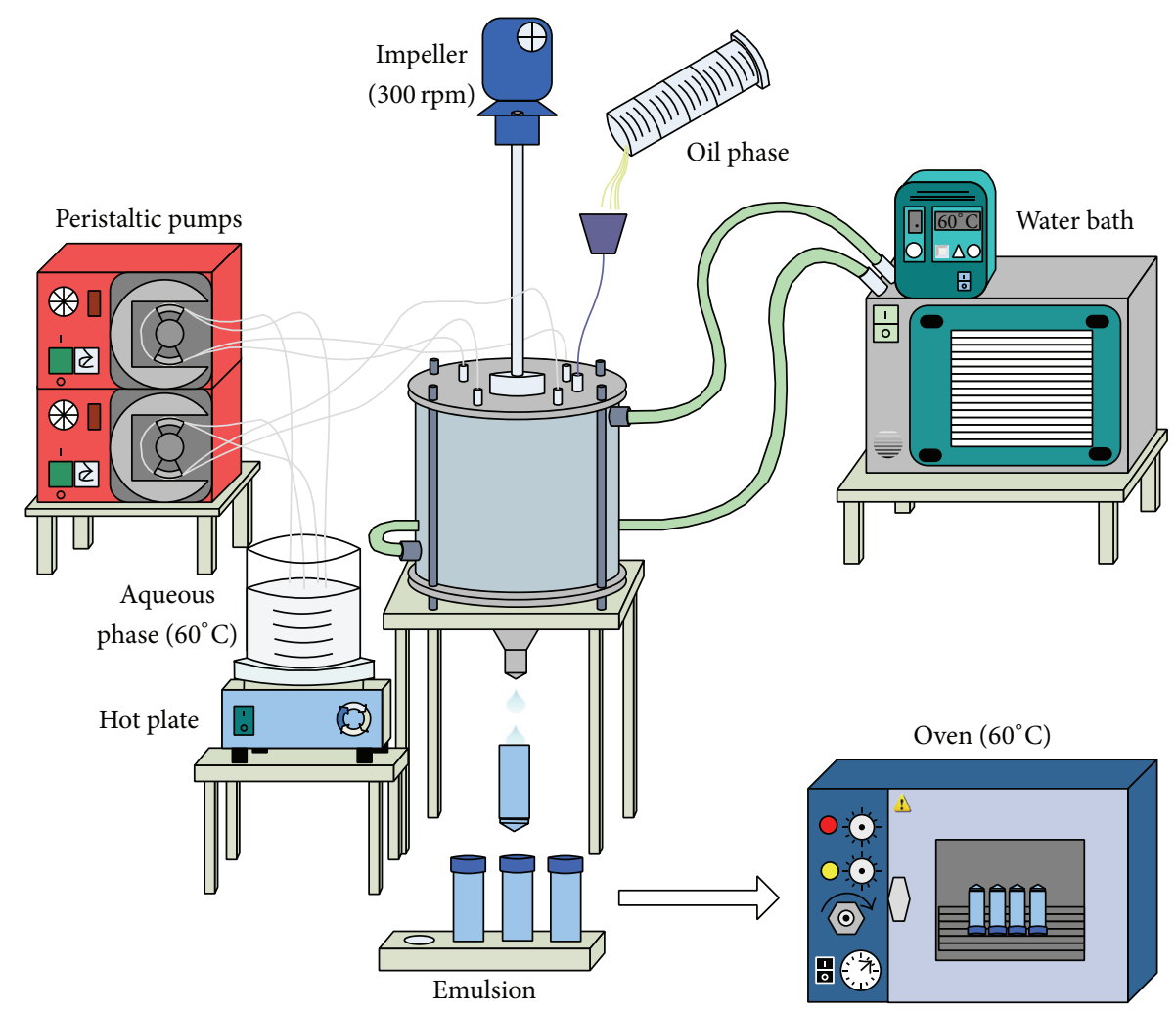

FIGURE 1: Schematic representation of PHP preparation adopted from [15].

minute for homogenization. The emulsion was then put into $50 \mathrm{~mL}$ plastic containers with internal diameters of $26 \mathrm{~mm}$ (Figure 1). The plastic containers were then placed in a preheated $\left(60^{\circ} \mathrm{C}\right)$ oven, where polymerization took place in about 8 hours. After the HIPE polymerized, the solidified PHP blocks were removed from the containers and cut into $4 \mathrm{~mm}$ thick disks with sharp razors. Drying of the disks did not require any specific equipment, as the disks were left to dry overnight on tissues in a fume cupboard. In order to remove the surfactant and residual monomer, the disks were washed in a Soxhlet extractor. First, they were washed with isopropanol for 3 hours, followed by another 3 hours of washing with double distilled water to clean any remaining residues in the pores and interconnecting walls. The pore size of the disks was evaluated by scanning electron microscopy.

2.2. Electroless Deposition Solution. The electroless deposition was conducted under flow conditions. Therefore, some of the common electroless deposition problems, such as constant change in $\mathrm{pH}$ (caused by hydrogen liberation during deposition) and difficulty to control reduction of free nickel, were not encountered. Hence, employment of buffering agents, inhibitors, or complexing agents was not required. The electroless deposition solution (plating bath) was composed of nickel source, reducing agent, and ammonium hydroxide to adjust the $\mathrm{pH}$. Sodium hypophosphite hydrate was used as a reducing agent. Accordingly, the plating bath compositions were very simple compared with the well-established plating bath compositions often used in commercial applications such as metal coating of plastic parts [25].

Metal Deposition Solutions (Plating Bath). Nickel chloride was used as the metal source. The main study is focused on the use of sodium hypophosphite as the reducing agent. However, in order to demonstrate the effect of reducing agent on the characteristics of metal deposition, we also used dimethylamine borane as the reducing agent.

\section{Plating Bath-1. Consider the following:}

(i) Metal source is nickel chloride, with fixed concentration at $[\mathrm{Ni}]=0.13 \mathrm{M}$.

(ii) Reducing Agent-1 is sodium hypophosphite hydrate $\left(\mathrm{NaH}_{2} \mathrm{PO}_{2} \cdot \mathrm{H}_{2} \mathrm{O}\right)$ with variable concentration at $[\mathrm{P}]=$ $0.13 \mathrm{M} ; 1.26 \mathrm{M} ; 2.52 \mathrm{M}$. Here, we represent the reducing agent concentration through the molar concentration of phosphorous.

(iii) $\mathrm{pH}$ regulator is ammonium hydroxide (35\% concentration) to set $\mathrm{pH}=11.5$.

Plating Bath-2. Consider the following:

(i) Metal source is nickel chloride, with fixed concentration at $[\mathrm{Ni}]=0.13 \mathrm{M}$.

(ii) Reducing Agent-2 is dimethylamine borane $\left[\left(\mathrm{CH}_{3}\right)_{2} \mathrm{NHBH}_{3}\right]$ at a fixed concentration of $[\mathrm{B}]=$ $0.26 \mathrm{M}$. 


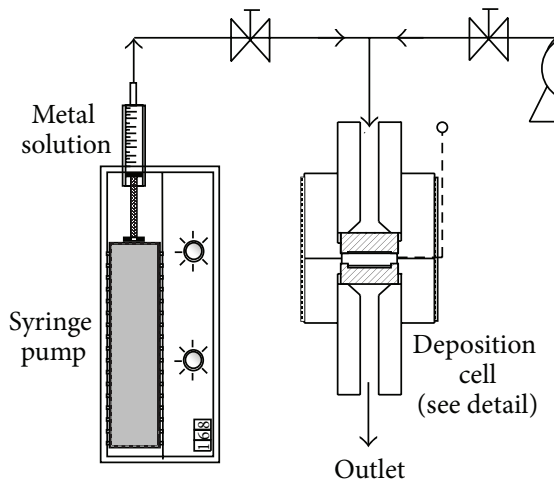

(a)

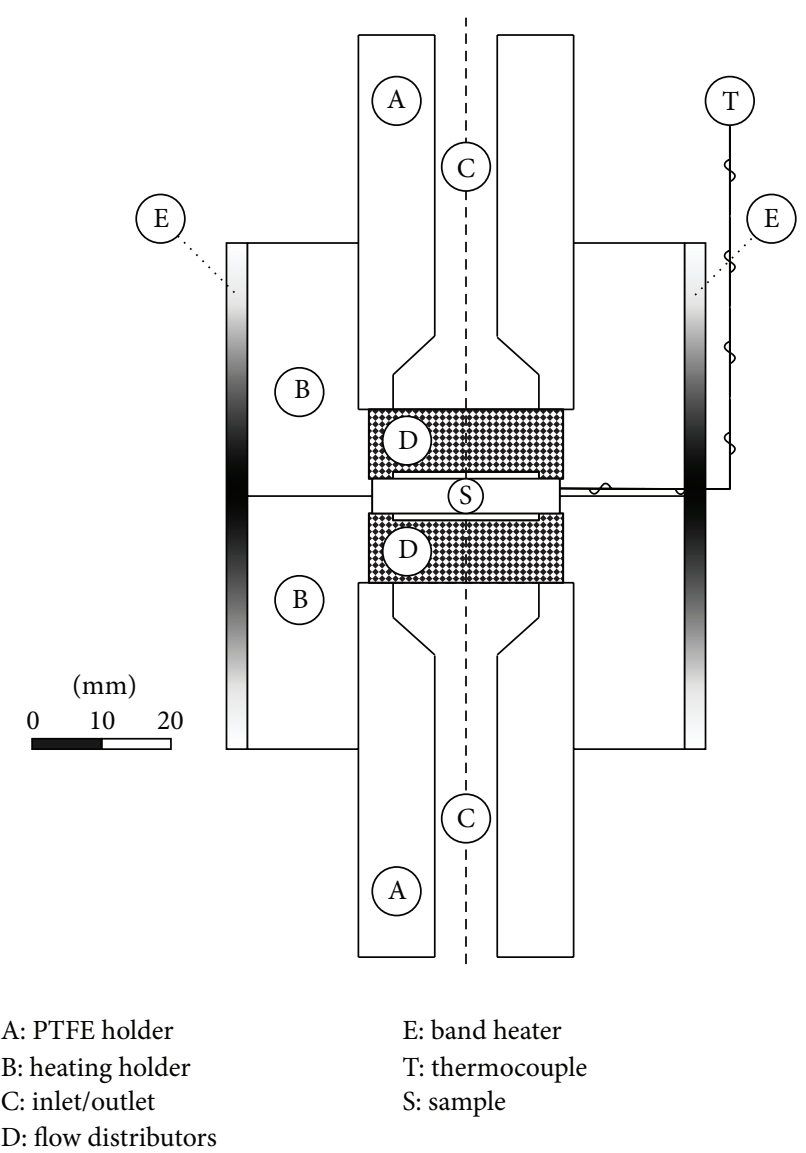

(b)

FIgURE 2: (a) Diagrammatic illustration of the metal deposition setup. (b) Details of the metal deposition cell.

(iii) Solution stabilizers are $0.27 \mathrm{M}$ sodium acetate and $3.88 \times 10^{-4} \mathrm{M}$ sodium lauryl sulphate.

(iv) $\mathrm{pH}$ regulator is ammonium hydroxide $(35 \%$ concentration) to set $\mathrm{pH}=7.5$.

2.3. Metal Deposition Process. The metal deposition setup used through this study is shown in Figure 2. The flow diagram of the metal deposition setup is shown in Figure 2(a). A metal deposition cell was constructed as illustrated in Figure 2(b). The deposition cell housed the template PHP in the form of a disk ( $4 \mathrm{~mm}$ thick and $26 \mathrm{~mm}$ in diameter). Referring to Figure 2(b), PHP template sample (S) was sandwiched between two PTFE flow distributors (D) at the end of the PTFE flow channel (C) bored into the holders (A) which also acted as support for PHP. The whole assembly was then placed between two circular brass blocks (B) which was electrically heated using a band heater (E). Note that the PHP template was in direct contact with the brass holder to provide direct heating. Temperature of the PHP template was monitored using a thermocouple $(\mathrm{T})$ in contact with the polymer. All parts of the flow cell which were in direct contact with the plating bath were made of PTFE in order to prevent metal deposition in the flow channels.
The metal deposition solution was kept at room temperature and was pumped into the deposition cell using a syringe driver at a rate of $2 \mathrm{~mL} / \mathrm{min}$. In order to cause metal deposition within the pores of the template polymer, the temperature of the solution was raised to $90 \pm 3^{\circ} \mathrm{C}$ in the polymer. In order to achieve this, the deposition cell was heated to $90^{\circ} \mathrm{C}$ by using the band heater and charged with dematerialized water at $97^{\circ} \mathrm{C}$ for 4 minutes at a rate of $40 \mathrm{~mL} / \mathrm{min}$. This was followed by the syringe pumping of the metal bath solution. After pumping $50 \mathrm{~mL}$ solution, the deposition was stopped and hot water washing was renewed and the cycle was repeated. Throughout the experiment, the band heater and hot water washing kept the polymer constantly at $90^{\circ} \mathrm{C}$. After using $340 \mathrm{~mL}$ metal bath solution, the direction of flow was reversed until a sufficient amount of metal was deposited. It is possible to reverse the flow direction after each $50 \mathrm{~mL}$ deposition and washing, in order to obtain more uniform deposition.

2.4. Heat Treatment. After the completion of the metal deposition and final washing, the samples were put into a high temperature oven and the temperature of the oven is increased from room temperature to the heat treatment temperature $(T)$ which was dominantly $600^{\circ} \mathrm{C}$. The heating rate 


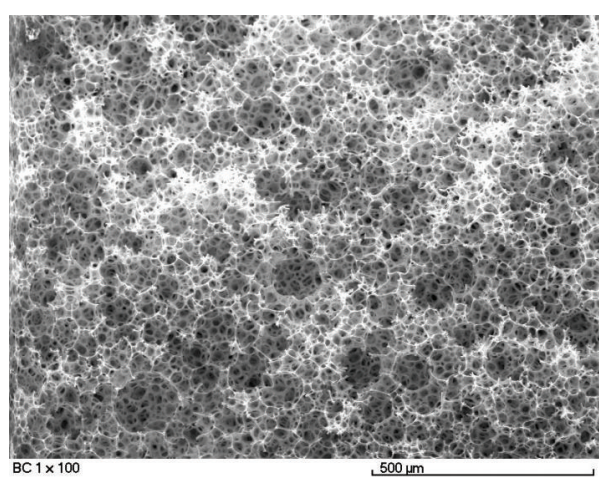

(a)

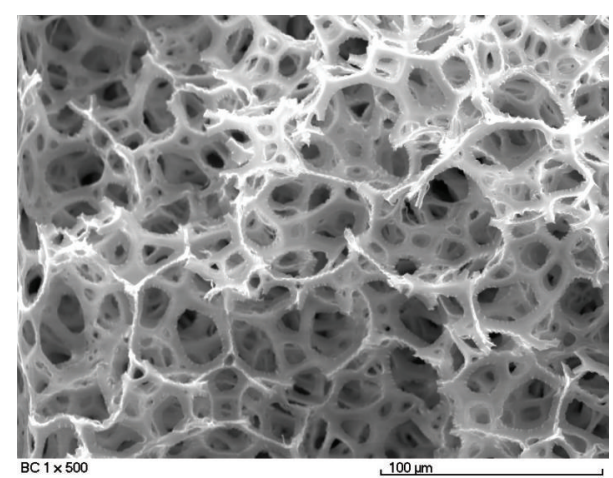

(b)

FIGURE 3: Pore morphology of the PHP disks, with porosity of $95 \%$ and average pore size of $55 \pm 5 \mu \mathrm{m}$ that were used in the metallization experiments: (a) general appearance (scale bar $=500 \mu \mathrm{m})$; (b) details (scale bar $=100 \mu \mathrm{m})$.

$\left(H_{r}\right)$ was such that total heating period was 1 hour. After reaching this heat treatment temperature, the samples were annealed at this temperature for a period of $t_{a}$. In the majority of cases, $t_{a}=60 \mathrm{~min}$.

2.5. Scanning Electron Microscopy (SEM) and Energy Dispersive $X$-Ray (EDX) Analysis. The scanning electron microscope used in the present work was an environmental scanning electron microscopy (XL30 ESEM-FEG) fitted with a Rontec Quantax system for energy dispersive X-ray (EDX) analysis to obtain local atomic concentration of various elements in metallic samples after heat treatment. Since the metallic samples were conductive, they were not coated although the nonconductive polymeric samples could also be examined in their natural state without significant sample modification or preparation. However, polymeric samples were coated with gold for SEM imaging.

2.6. X-Ray Diffraction (XRD). The X-ray diffraction (XRD) equipment was a PANalytical X'Pert Pro diffractometer, fitted with an $\mathrm{X}^{\prime}$ Celerator. The $\mathrm{X}^{\prime}$ Celerator is a relatively new attachment to the X'Pert and has the effect of giving a good quality pattern in a fraction of the time of the traditional diffractometer.

2.7. BET Surface Area Analysis. A Beckman-Coulter SA 3100 analyzer was used. This instrument uses the gas sorption technique to obtain the surface area and pore size distributions at room temperature using helium. Specific surface area of the metallized monoliths was calculated after measuring bulk density of the samples in order to compare these materials with the commercially available porous metals.

2.8. Mercury Porosimetry. In this study, the mercury intrusion porosimetry technique was used to measure the porosity and pore size distribution of the metal foams. The equipment (Autopore II 9220) was manufactured by Micromeritics Ltd.

\section{Results and Discussion}

Our aim is to demonstrate the feasibility of obtaining monolithic metal foams which can also be used as catalytic reactors or as supported membranes. Therefore, in the first instance, we aim to establish the method of production which can be scaled up, evaluate the mechanism of electroless deposition as well as nanostructure formation through heat treatment, and evaluate the characteristics of the metallic monoliths with a hierarchic pore structure in which the pore size ranges from nanometers to micrometers. For this purpose, we used a nickel chloride/hypophosphite system in a very simple deposition solution which did not contain any stabilizers and surface sensitization (by palladium) of the template deposition medium (i.e., PHP) to promote deposition and reduction reactions.

3.1. PolyHIPE Polymer Templates. Throughout this study, we used one type of PolyHIPE Polymer (PHP) template with phase volume $95 \%$, pore size $55 \pm 2 \mu \mathrm{m}$. A scanning electron micrograph of the PHP template is shown in Figure 3. We have chosen this material because smaller pore size or phase volume PHP requires pressurization to pump the metal deposition solution and it does not allow the deposition of sufficient metal to provide mechanical strength.

3.2. Metal Deposition Characteristics. The deposition of metal within the pores is in the form of metal grains. Figures 4(a) and 4(b) illustrate the metal deposition behavior, in which the metallic grains as well as the polymer structure can be identified clearly as the deposition is at the early stages of the experiments ( $340 \mathrm{~mL}$ solution passed). The deposition was carried out until all the strands of the polymer were totally covered with metal grains which required $600 \mathrm{~mL}$ solution in this example illustrated in Figure 4(b). The weight of a typical construct (template polymer and nickel deposit) was $3.2 \mathrm{~g}$ when the deposition was stopped. An example of a fully deposited polymer disk is shown in Figure 4(b) which indicates the autocatalytic nature of the deposition kinetics. Initial deposition rate was low since the template polymer was not sensitized and the size of the metal grains was some $70 \%$ larger compared with the average size of the grains deposited at the later stages as shown in Figure 4(a).

$\mathrm{X}$-ray diffraction patterns of the electroless Ni-P grains in the as-deposited condition are given in Figure 5 which 


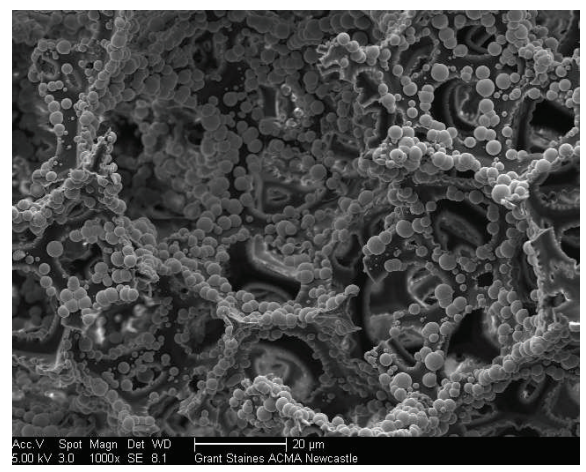

(a)

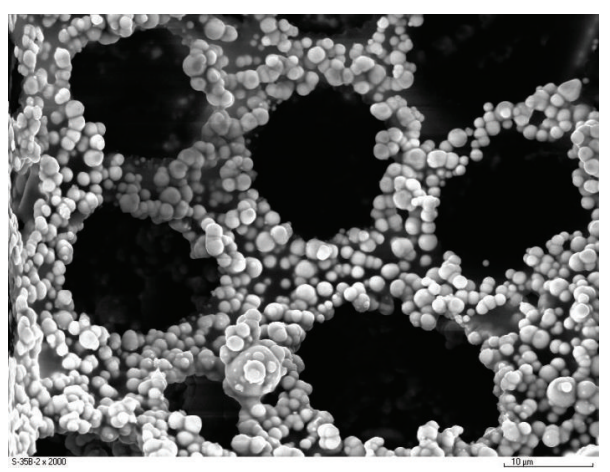

(b)

FIGURE 4: Nickel deposition from $\mathrm{NiCl}_{2}[\mathrm{Ni}]=0.13 \mathrm{M}$ solution with sodium hypophosphite as reducing agent $[\mathrm{P}]=2.52 \mathrm{M}$. (a) Inner structure at the early stages of deposition, after passing $300 \mathrm{~mL}$ solution through the template when the dry weight of the resulting construct (PolyHIPE Polymer and metal deposit) was $0.87 \mathrm{~g}$ (scale bar $=20 \mu \mathrm{m}$ ). (b) Inner structure after passing $600 \mathrm{~mL}$ solution when the weight of the resulting construct was $3.2 \mathrm{~g}$ (scale bar $=10 \mu \mathrm{m})$.

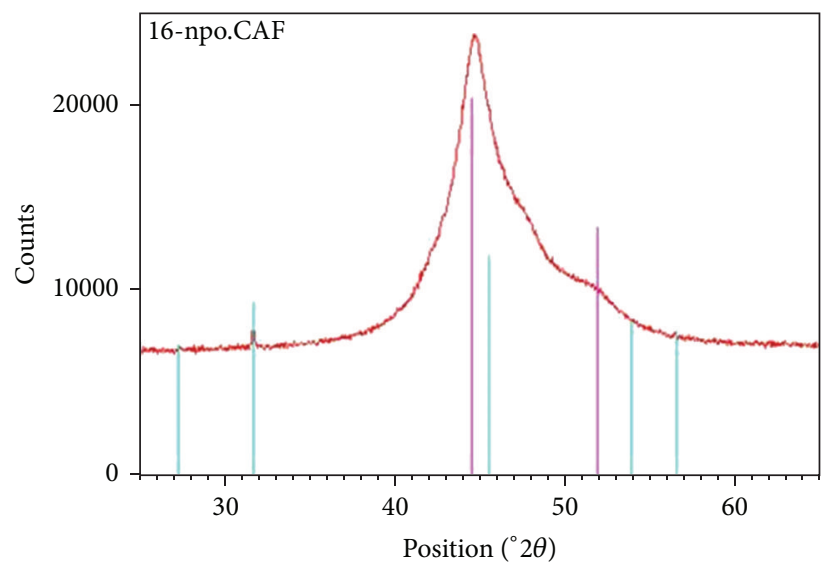

\begin{tabular}{|l|l|}
\hline Peak list & \\
\hline 04-0850; Ni; nickel, syn & \\
\hline $05-0628$, Na Cl, balte, syn & \\
\hline
\end{tabular}

FIGURE 5: XRD pattern of the as-deposited Ni-P grains before heat treatment of the construct obtained through nickel deposition using a plating bath with $0.13 \mathrm{M} \mathrm{NiCl}_{2}$ and $1.26 \mathrm{M}$ sodium hypophosphite after using $600 \mathrm{~mL}$ solution.

exhibited a single broad peak indicative of the amorphous nature of the metal deposits. It also indicates the presence of small amounts of $\mathrm{NaCl}$ generated during the reduction of $\mathrm{NiCl}_{2}$ by $\mathrm{NaH}_{2} \mathrm{PO}_{3}$.

The effect of reducing agent concentration $[\mathrm{P}]$ in the metal deposition solution on the size of the nickel-phosphorous grains is illustrated in Figure 6. The grain size decreased with increasing reducing agent concentration. Regarding the sizes of the deposits, Ni-P grain diameters ranged from 7 to $18 \mu \mathrm{m}$, from 2.5 to $10.5 \mu \mathrm{m}$, and from 0.75 to $2 \mu \mathrm{m}$ when the reducing agent concentration increased from 0.63 to 1.26 and then to $2.52 \mathrm{M}$.
As seen in these micrographs, the concentration of deposited grains increases with increasing reducing agent concentration. In order to illustrate the effect of the type of reducing agent on grain size, we also used $0.63 \mathrm{M}$ borane dimethylamine instead of sodium hypophosphite. As seen in Figure 6(d), the grain size for borane dimethylamine is ca. $200 \mathrm{~nm}$.

3.3. Heat Treatment and Skin-Core Structure Development. In order to understand the mechanism of structure formation in these constructs (i.e., template PolyHIPE Polymer and metal deposit) after passing $600 \mathrm{~mL}$ plating bath solution through the template PolyHIPE Polymer, the resulting samples were heat-treated. In these experiments, we used $0.13 \mathrm{M}$ nickel chloride and $1.26 \mathrm{M}$ reducing agent and sodium hypophosphite. After full deposition was achieved (weight of the washed and dried constructs was typically $3.2 \mathrm{~g}$ ), the resulting constructs were washed in water and then heat-treated.

Starting from room temperature, the sample already in the oven, temperature was increased to a prescribed temperature at a variable rate so that the heating period was 60 minutes. After reaching the target temperature (i.e., 500, 600, and $800^{\circ} \mathrm{C}$ ), samples were either removed immediately (so that annealing time $t_{a}=0$ ) and subsequently cooled to the room temperature in air or alternatively kept at the target temperature for a fixed period of time (usually $60 \mathrm{~min}$ ) and then removed from the oven and allowed to cool down in air. Final heat treatment procedure involved a prolonged annealing. After reaching the heat treatment temperature and remaining at this temperature for 60 minutes $\left(t_{a}=60 \mathrm{~min}\right)$, the heating was switched off and the samples were gradually cooled in the oven over a period of 12 hours.

The reason for this heat treatment protocol was to understand the structure formation as a result of the solid-state reaction that took place during heat treatment. The fracture surface of these heat treated samples was examined under scanning electron microscopy (SEM). The location of the examination was typically at the center of the samples in all cases. The reason for this is that these monoliths form 


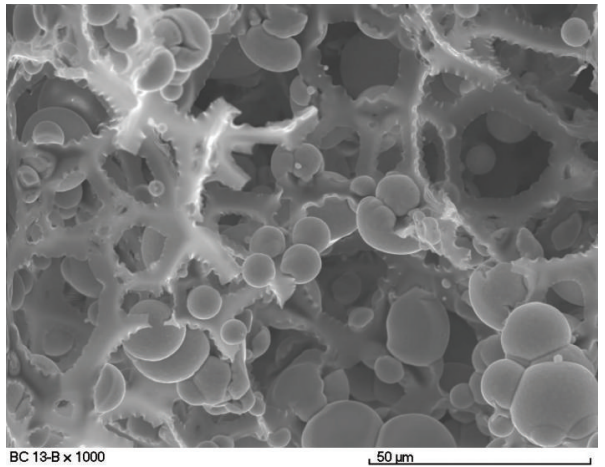

(a)

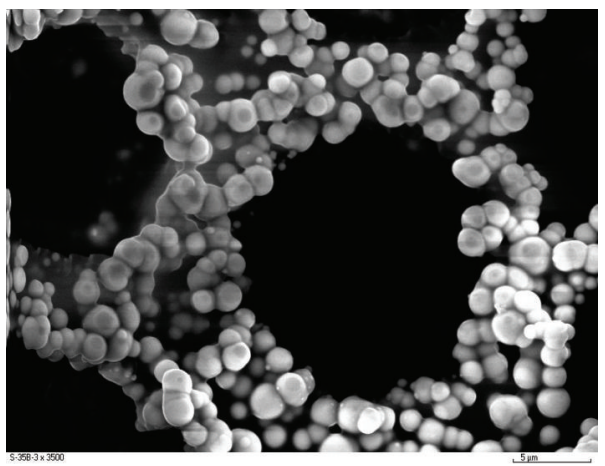

(c)

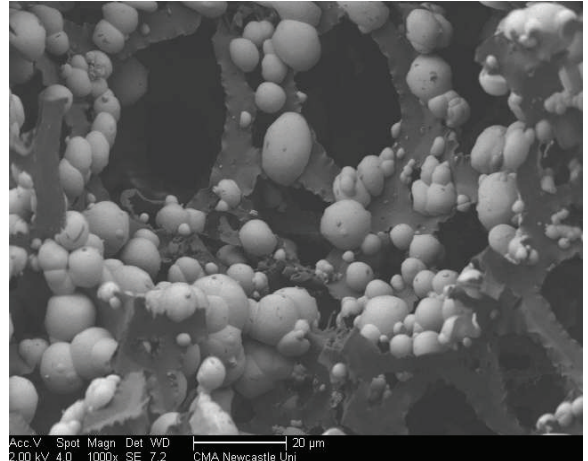

(b)

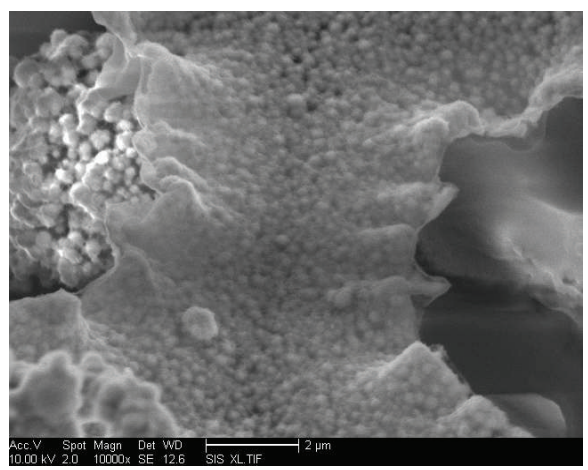

(d)

FIGURE 6: Size of the spherical grain deposits varied depending on the concentration of the plating bath. Amount of the reducing agent sodium hypophosphite and volume of solution used were (a) $0.63 \mathrm{M}$ and $200 \mathrm{~mL}$, (b) $1.26 \mathrm{M}$ and $200 \mathrm{~mL}$, and (c) $2.52 \mathrm{M}$ and $600 \mathrm{~mL}$. (d) In this example, we also used $0.26 \mathrm{M}$ dimethylamine borane as the reducing agent and $600 \mathrm{~mL}$ solution was used. Regarding the size of the deposits, (a) Ni-P grain diameters ranged from 5 to $20 \mu \mathrm{m}$, (scale bar $=50 \mu \mathrm{m}$ ); (b) Ni-P grain diameters ranged from 2 to $12 \mu \mathrm{m}$, (scale bar $=$ $20 \mu \mathrm{m}$ ); (c) Ni-P grain diameters ranged from 0.5 to $2 \mu \mathrm{m}$ (scale bar $=5 \mu \mathrm{m}$ ); (d) Ni-B grain diameters were in the order of a few hundred nanometers (scale bar $=2 \mu \mathrm{m})$.

a skin/core structure in which the skin has reduced porosity but provides strength to the monolith. These results are illustrated in Figures 7(a)-7(f) which reveal the mechanism of structure formation through a solid state reaction.

The transformation of the Ni-P grains began on the surface of the grains. As the reaction proceeded, dense metallic strands appeared which eventually covered the inner part of the grains (Figures 7(a)-7(d)). These strands also fused but formed a porous skin (Figure $7(\mathrm{e})$ ) with pore size of ca. $200 \mathrm{~nm}$ and thickness ca. $1 \mu \mathrm{m}$. Further SEM examination of the fracture surface of the grains indicated that core of the grains is phase separated from the porous skin (Figure 7(e)). During heat treatment, the original discrete spherical grains now merged to form a continuous undulating capillary with porous walls forming the walls of the micron sized large pores which are connected to each other through micron size arterial interconnecting windows.

Figures $7(\mathrm{a})-7(\mathrm{f})$ show that, during heat treatment, the fused grains forming the walls of the porous monolith undergo a solid-state reaction which also causes a phase separation, resulting in a porous skin and a detached core. However, as these grains are all connected, the resulting wall structure is in the form of undulating porous capillaries filled with nickel-phosphorus compound as revealed by XRD and energy dispersive X-ray analysis.

When the core material was removed from the broken grain skin, the remaining structure looked like an empty shell. Extensive SEM examination indicated that these grains fuse together to form undulating partially filled capillaries. These structures can be termed as "capillary-like, or capillaric" and indeed they are also formed in nature as part of angiogenesis $[32,33]$. The materials within these capillaries are the unreacted $\mathrm{Ni}-\mathrm{P}$ compounds $\mathrm{Ni}_{2} \mathrm{P}, \mathrm{Ni}_{12} \mathrm{P}_{5}$, and $\mathrm{Ni}_{3} \mathrm{P}$, with the latter being the most stable of these Ni-P compounds as shown later using XRD. The inner part of the grain skin (shell) can be seen in Figure 8(a). As this structure was examined in more detail, it was observed that the inner part of grain skin was composed of nanosized pores as shown in Figure 8(b).

3.4. Structure of the Grains and Capillaric Walls of the Arterial Pores. After heat treatment, the formation of a grain skin around the core was not the only change in the solid deposits. The core material itself was also subjected to reaction and a second skin appeared in the grains. The presence of multiple skins was only observed when the reducing agent concentration was high $([\mathrm{P}]=1.26$ or $2.52 \mathrm{M})$. This feature can 


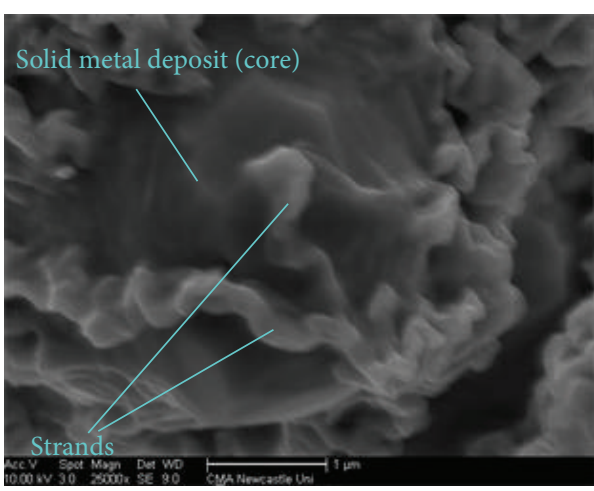

(a)

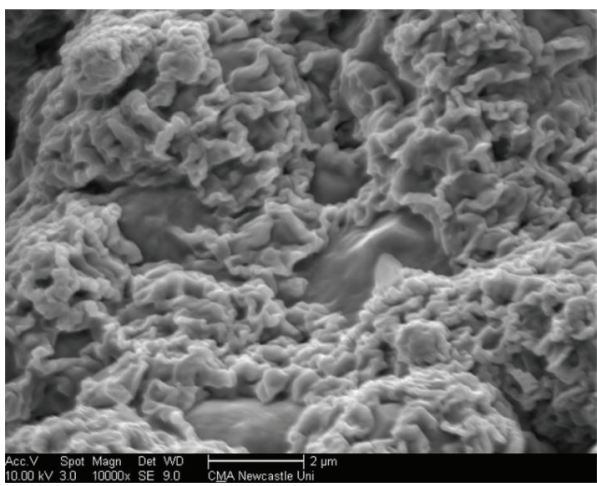

(c)

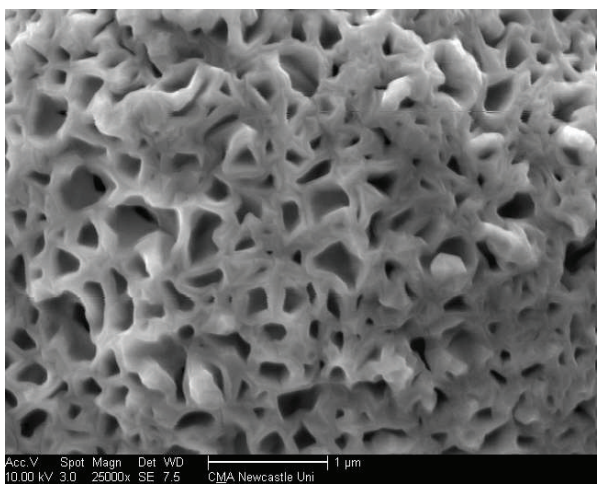

(e)

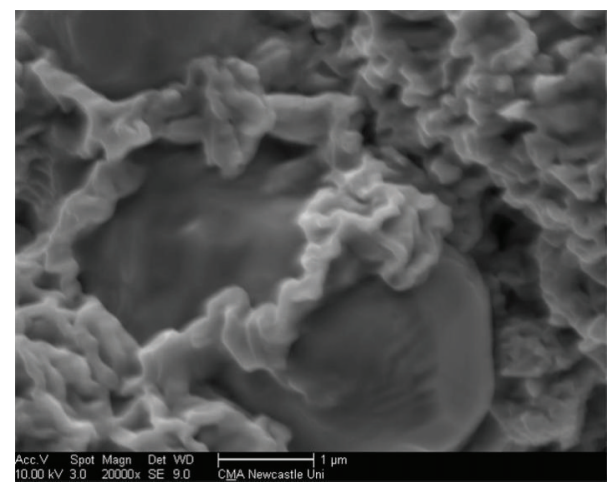

(b)

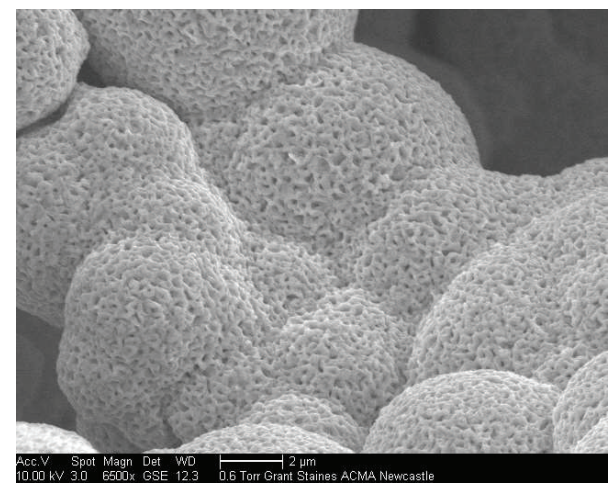

(d)

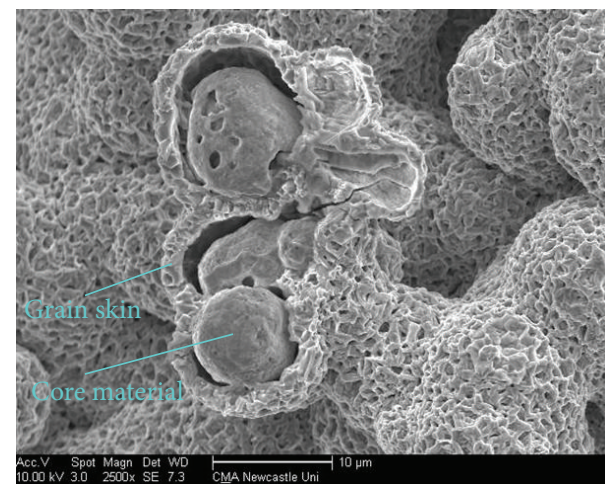

(f)

Figure 7: Development of hierarchic pore structure during heat treatment of the Ni-P metal deposits. Sample characteristics: [Ni] = 0.13 M; $[\mathrm{P}]=1.26 \mathrm{M}$. Amount of deposition solution used was $600 \mathrm{~mL}$. (a) First stage of the formation of grain surface skin after temperature reached $T=500^{\circ} \mathrm{C}$ during heating at $H_{r}=10^{\circ} \mathrm{C} / \mathrm{min} ; t_{a}=0$. (scale bar $=1 \mu \mathrm{m}$ ). (b) Skin formation after temperature reaches $T=600^{\circ} \mathrm{C}$ during heating at $H_{r}=10^{\circ} \mathrm{C} / \mathrm{min} ; t_{a}=0$. (scale bar $=1 \mu \mathrm{m}$ ). (c) Skin formation after temperature reaches $T=600^{\circ} \mathrm{C}$ during heating at $H_{r}=10^{\circ} \mathrm{C} / \mathrm{min}$; $t_{a}=15 \mathrm{~min}$ (scale bar $=2 \mu \mathrm{m}$ ). (d) Full grain skin formation after heat treatment at $T=600^{\circ} \mathrm{C}$ when $H_{r}=10^{\circ} \mathrm{C} / \mathrm{min} ; t_{a}=60$ min followed by cooling in the closed oven until reaching room temperature over a period of 12 hours (scale bar $=2 \mu \mathrm{m}$ ). (e) Details of the skin at high magnification (sample as in Figure 7(d)) showing the existence of the pores with size ca. $200 \mathrm{~nm}$ (scale bar $=1 \mu \mathrm{m})$. (f) The inner structure of the grains revealed by the fractured grains showing a porous skin and a dense inner core. Sample same as in Figure $7(\mathrm{~d})(\mathrm{scale}$ bar $=10 \mu \mathrm{m})$.

be best explained by the expression "Russian doll" structure as shown in Figure 9. The sample in Figure 9 had a grain size of ca. $12 \mu \mathrm{m}$. The first skin had a thickness of ca. $2 \mu \mathrm{m}$ while the thickness of the second skin was ca. $1 \mu \mathrm{m}$. These skins were separated from each other although the second skin was connected in part to the inner unreacted core which had a diameter of ca. $6 \mu \mathrm{m}$. The erosion of the core can be observed in the SEM image at high magnification in Figure 9.
As the grains got smaller in size, they became more difficult to find broken cores to be examined. Innermost cores as small as $0.5 \mu \mathrm{m}$ were observed in other samples as seen in Figure 10 which also indicates that the capillary-like (capillaric) walls of the arterial pores have large porosity.

Inward oxygen diffusion and oxygen gas transport through the voids and microchannels in the $\mathrm{NiO}$ scale resulted in the formation of a duplex $\mathrm{NiO}$ structure [34-37]. 

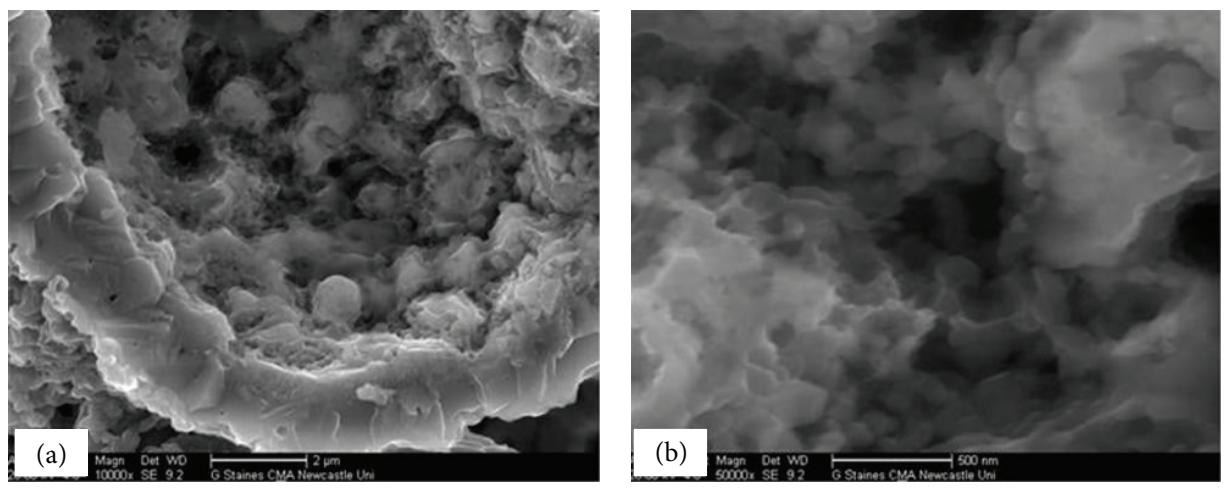

FIGURE 8: Details of the porous undulating capillaries forming the walls of the large arterial pores. Sample characteristics: [Ni] $=0.13 \mathrm{M}$; $[\mathrm{P}]=1.26 \mathrm{M}$. Amount of deposition solution used was $600 \mathrm{~mL}$. Heat treatment conditions: $T=600^{\circ} \mathrm{C}$ during heating at $H_{r}=10^{\circ} \mathrm{C} / \mathrm{min}$; $t_{a}=60 \mathrm{~min}$. (a) Inner structure of an empty capillary wall (Scale bar $2 \mu \mathrm{m}$ ). (b) Details of the inner structure of the capillary walls of the arterial pores (scale bar $=500 \mathrm{~nm}$ ).

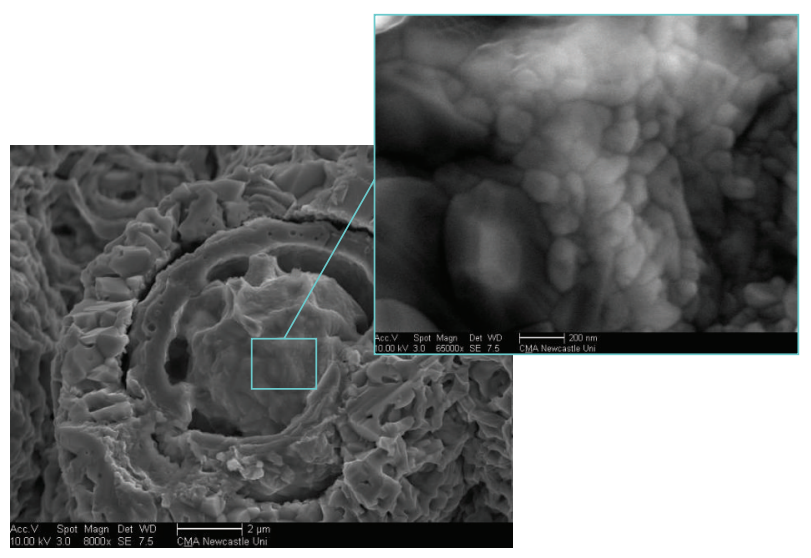

FIGURE 9: Russian doll structures after heat treatment when $[\mathrm{Ni}]=0.13 \mathrm{M},[\mathrm{P}]=1.26 \mathrm{M}$, Heat treatment temperature $T=800^{\circ} \mathrm{C}$ (heating rate $H_{r}=13^{\circ} \mathrm{C} / \mathrm{min}$ ), and annealing time $t_{a}=60 \mathrm{~min}$ followed by cooling in air. Scale bar $=2 \mu \mathrm{m}$ and $200 \mathrm{~nm}$ (scale bar of inset).

Further inward oxygen diffusion and oxygen transport can also cause triplex or quadruplex oxide scale formation. The balance between oxygen supply (activity) and phosphorus content determines exactly which structures form at which time during oxidation. Formation of a complete $\mathrm{NiPO}_{x}$ layer between $\mathrm{Ni}-\mathrm{P}$ and $\mathrm{NiO}$ layers must be validated by further investigation with TEM.

The summary of the effect of reducing agent concentration on the grain structure is given in Table 1 .

Although it can be clearly seen that the grain sizes decrease with increasing sodium hypophosphite molarity, there is not a uniform distribution of grain sizes before or after the heat treatment. However, after heat treatment, the sample produced by using $0.63 \mathrm{M}$ sodium hypophosphite had the most regular size and shape of grains. When $2.52 \mathrm{M}$ sodium hypophosphite was used as a reducing agent, a very high degree of sintering/agglomeration of the grains was observed. Grain surface pore size was similar in the first two

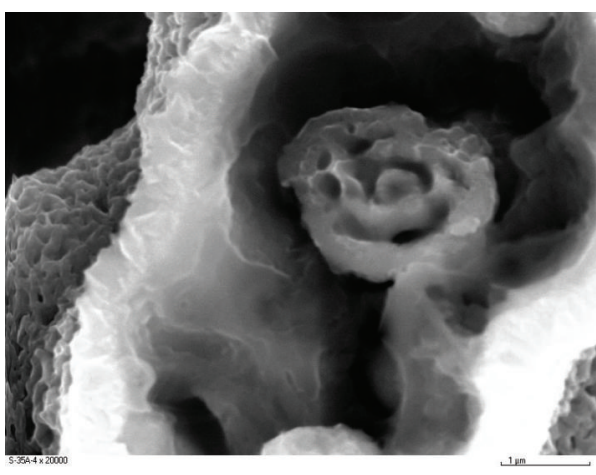

FIGURE 10: Formation of capillaric walls of the arterial pores after heat treatment following the solid state oxidation of $\mathrm{Ni}_{x} \mathrm{P}_{y}$ compounds in the grains. Sample characteristics: $[\mathrm{Ni}]=0.13 \mathrm{M}$, $[\mathrm{P}]=2.52 \mathrm{M}$, heat treatment temperature $T=600^{\circ} \mathrm{C}$ (heating rate $H_{r}=10^{\circ} \mathrm{C} / \mathrm{min}$ ), and annealing time $t_{a}=60 \mathrm{~min}$ followed by cooling in air. Scale bar $=1 \mu \mathrm{m}$.

TABLE 1: The properties of three samples prepared by using [Ni] $=0.13 \mathrm{M}$ and sodium hypophosphite as reducing agent at concentrations $[\mathrm{P}]=0.63 \mathrm{M}, 1.26 \mathrm{M}$, and $2.52 \mathrm{M}$. Heat treatment was conducted with gradual heating from room temperature to $600^{\circ} \mathrm{C}$ at a rate of $10^{\circ} \mathrm{C} / \mathrm{min}$ followed by annealing at $600^{\circ} \mathrm{C}$ for 60 minutes and cooling in air.

\begin{tabular}{lccc}
\hline $\begin{array}{l}\text { Sodium hypophosphite } \\
\text { concentration }(\mathrm{M})\end{array}$ & 0.63 & 1.26 & 2.52 \\
\hline $\begin{array}{l}\text { Grain size }(\mu \mathrm{m}) \\
\text { Before heat treatment }\end{array}$ & $5-10$ & $2-11$ & $0.5-2$ \\
\hline $\begin{array}{l}\text { Grain size }(\mu \mathrm{m}) \\
\text { After heat treatment }\end{array}$ & $6-12$ & $3-12$ & $0.5-4$ \\
\hline $\begin{array}{l}\text { Grain surface pores }(\mathrm{nm}) \\
\text { After heat treatment }\end{array}$ & $100-400$ & $100-400$ & $20-200$ \\
\hline
\end{tabular}

samples. The high concentration of sodium hypophosphate decreased the size of the surface pores drastically although these pores were not well defined. 


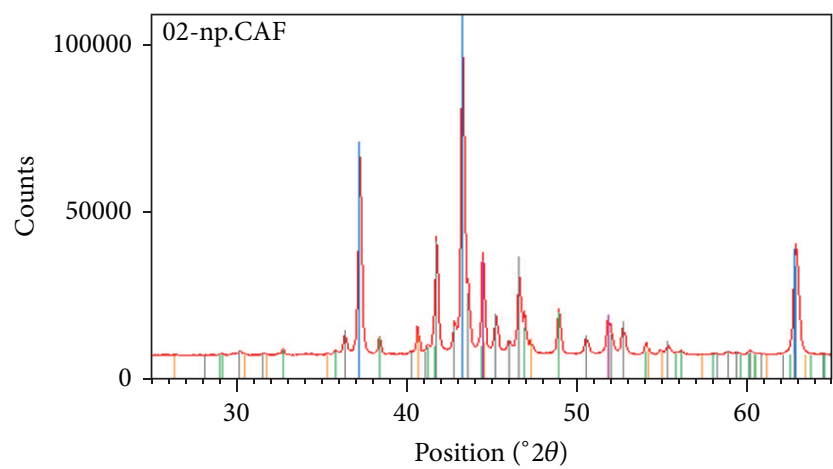

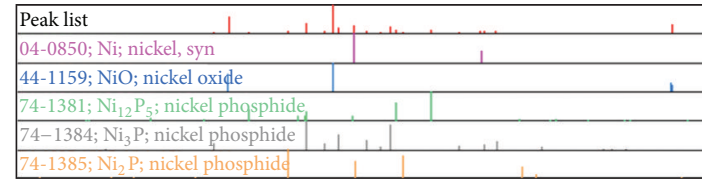

FIgURE 11: XRD pattern of the Ni-P structure (same sample in Figure 10) after heat treatment at $600^{\circ} \mathrm{C}$. Sample details: plating bath composition: $[\mathrm{Ni}]=0.13 \mathrm{M},[\mathrm{P}]=1.26 \mathrm{M}$ and heat treatment conditions: $T=600^{\circ} \mathrm{C}$, heating rate $=10^{\circ} \mathrm{C}$, and curing/annealing time $t_{c}=60 \mathrm{~min}$ followed by cooling in air.

3.5. Chemical Distribution within Grains: XRD and EDX Analysis. In order to obtain the overall chemical composition of the porous monoliths after heat treatment, the XRD patterns are taken. These patterns change with plating bath composition and heat treatment. A typical XRD pattern of the whole sample is shown in Figure 11. The sharp XRD peaks indicate crystalline structure formed by various compounds which were identified as $\mathrm{Ni} ; \mathrm{NiO} ; \mathrm{Ni}_{12} \mathrm{P}_{5} ; \mathrm{Ni}_{3} \mathrm{P}$; and $\mathrm{Ni}_{2} \mathrm{P}$. Although XRD study is useful in the identification of the compounds and their crystal structure, the distribution of nickel, oxygen, and phosphorous across the grains and indeed in different locations was studied using energy dispersive $\mathrm{X}$ ray (EDX) analysis.

For EDX analysis, we used 3 different samples produced under different conditions and an additional sample was tested as a duplicate to test the reproducibility of the method. A grain in the sample chosen and its center was located under SEM. Several EDX measurements were performed at various distances from the center of the grain. This scheme is illustrated in Figure 12.

From the EDX spectrum, atomic fractions of nickel, oxygen, and hosphorous were calculated. The results are shown in Figure 13 where the atomic weight percent of phosphorous is plotted as a function of distance from the center of the grain. The range of overall phosphorous concentration in the samples before heat treatment ranged from 10.5 to 15.4 atomic percent (at\%) when the phosphorous concentration in the plating bath ranged from 0.63 to $2.52 \mathrm{M}$. As seen in Figure 13, the maximum phosphorous concentration is ca. 16 at\% although phosphorous concentration in the plating bath was $0.63 \mathrm{M}$ and $1.52 \mathrm{M}$. As discussed earlier, not all of the reducing agents are utilized in the reduction of sodium hypophosphite to $\mathrm{Ni}[26]$ and it therefore appears that the effect of the reducing agent is to change the morphology of

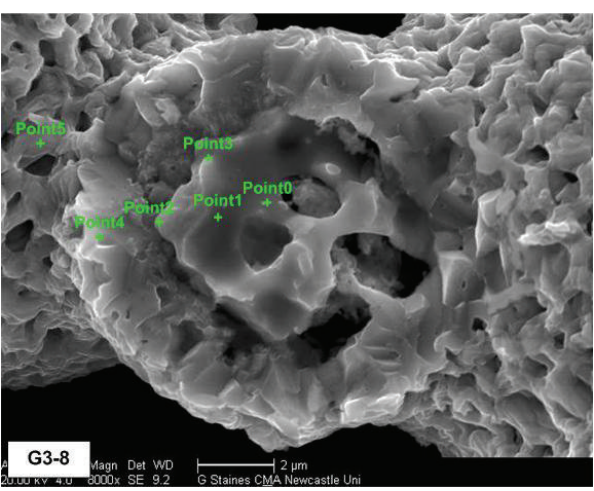

FIGURE 12: Typical example of the EDX analysis on a fractured grain using spot measurements starting from the center of the grain (Point 0 ) as a function of distance from the center. Sample characteristics: $[\mathrm{Ni}]=0.13 \mathrm{M},[\mathrm{P}]=1.26 \mathrm{M}$, heat treatment temperature $T=600^{\circ} \mathrm{C}$, heating rate $H_{r}=10^{\circ} \mathrm{C} / \mathrm{min}$, and annealing time $t_{a}=60 \mathrm{~min}$ followed by cooling in air. Scale bar $=2 \mu \mathrm{m}$.

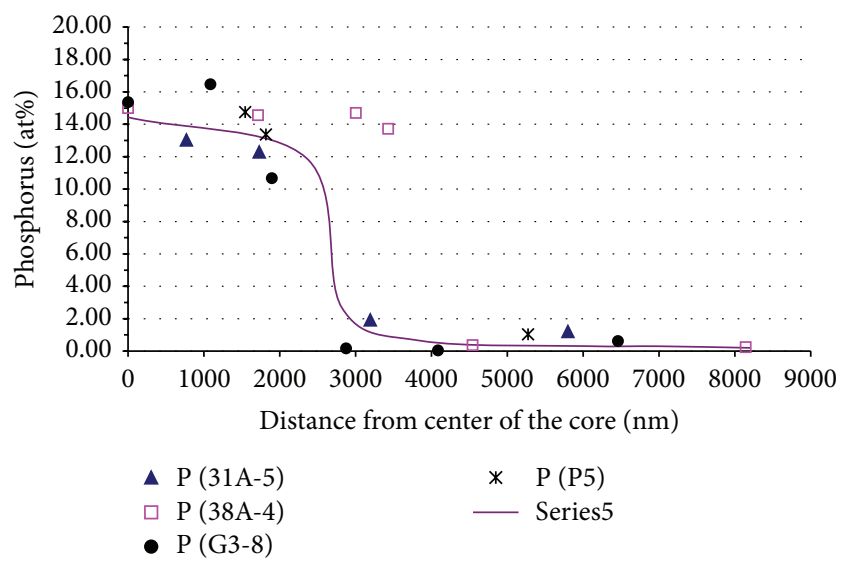

FIGURE 13: Distribution of phosphorus in grains as a function of distance from the center of the grain. Identification of the samples: Sample 31A: $[\mathrm{P}]=0.63 \mathrm{M}, \mathrm{T}=600^{\circ} \mathrm{C}$, and $t_{a}=60 \mathrm{~min}$; Sample 38A: $[\mathrm{P}]=1.26 \mathrm{M}$ and $T=800^{\circ} \mathrm{C}$; Samples G3 and P5: $[\mathrm{P}]=1.26 \mathrm{M}$ and $T=600^{\circ} \mathrm{C}$. In all cases, time to reach the heat treatment temperature is 60 minutes and curing/annealing time $t_{a}=60 \mathrm{~min}$ followed by cooling in air.

the grains (and hence the structure of the monolith) rather than change the chemical composition of $\mathrm{Ni}_{x} \mathrm{P}_{y}$ compounds. In commercial applications for nickel coating of plastic surfaces, the phosphorous content also ranges from ca. 4.6 to 23.1 at $\%$.

It is clear from Figure 13 that, within the core of the grains, phosphorous concentration remains constant but it is reduced sharply outside the core when the skin is reached where it is typically less than 1 at $\%$, within the accuracy of the experiments.

3.6. Overall Structure of the Monoliths: Crust Formation. The foregoing analysis of the foam structure was performed near the center of the monolith in order to illustrate the mechanism of structure formation. However, for practical purposes, 

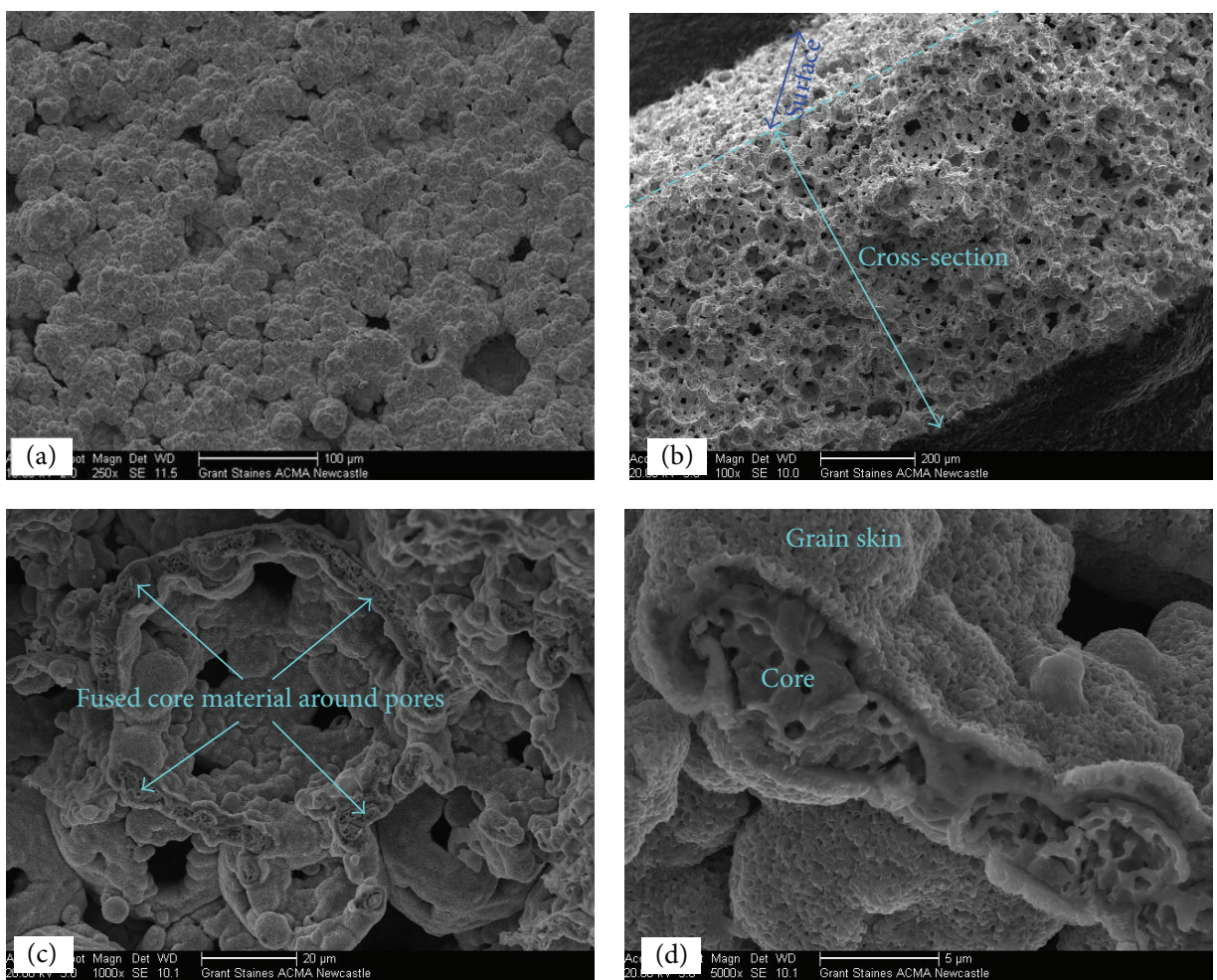

FIGURE 14: Structure of the skin produced on the top and bottom surface of the monoliths after heat treatment. Sample characteristics: $[\mathrm{Ni}]=0.13 \mathrm{M} ; \mathrm{P}]=1.26 \mathrm{M} ; T=600^{\circ} \mathrm{C}, H_{r}=10^{\circ} \mathrm{C} / \mathrm{min} ; t_{a}=60 \mathrm{~min}$ followed by cooling in air. (a) General appearances of top surfaces of metal disks after heat treatment. (b) Cross-section of the crust. (c) Large pore was formed by the fusion of numerous grains. All the core material in these grains was fused to form one extended core surrounding the large pores. (d) Details of how the core material and grain skin were shared. As a result, the core can be obtained in tubular form with very high porosity.

the mechanical strength of the monoliths is important and hence the full structure evaluation is necessary.

It was found that, even at the initial stages of metal deposition, a dense layer is formed on the surface of the template PolyHIPE Polymer. This dense layer is described as "crust" as it can be separated from the inner bulk of the monolith although both regions are connected. Crust is formed on both sides of the template when the flow direction is reversed as well as around the perimeter of the circular monoliths as plating bath solution leaks through the sides of the template disk. When these polymer/metal constructs are heat-treated, the resulting porosity of the dense layer (crust) is considerably smaller than that of the inner structure. Figure 14 illustrates the structure of crust after heat treatment at $600^{\circ} \mathrm{C}$ of a typical monolith with crust.

The thickness (crust) is dependent on the plating bath composition as well as on the deposition conditions. Furthermore, by using another nickel source (such as $\mathrm{NiSO}_{4}$ ), the dense crust layer can be completely eliminated.

It is possible to isolate the crust from the bulk and examine its structure separately. Figure 14(a) illustrates the surface appearance of the crust indicating the reduced porosity of the surface. The cross-section of the crust is shown in Figure 14(b) which shows that the porosity of the crust increases with distance from the surface. This is further illustrated in Figure 14(c) at larger magnification.
TABLE 2: Energy dispersive X-ray analysis of the crust. Variation of $\mathrm{Ni}, \mathrm{O}$, and $\mathrm{P}$ concentration as a function of distance from the top surface of the crust. $\left([\mathrm{Ni}]=0.13 \mathrm{M} ;[\mathrm{P}]=1.26 \mathrm{M} ; T=600^{\circ} \mathrm{C}, H_{r}=\right.$ $\left.10^{\circ} \mathrm{C} / \mathrm{min} ; t_{c}=60 \mathrm{~min}\right)$.

\begin{tabular}{lccc}
\hline $\begin{array}{l}\text { Distance from the } \\
\text { crust surface }(\mu \mathrm{m})\end{array}$ & $\begin{array}{c}\text { Nickel } \\
(\text { at\% })\end{array}$ & $\begin{array}{c}\text { Oxygen } \\
\text { (at\%) }\end{array}$ & $\begin{array}{c}\text { Phosphorous } \\
(\text { at\% })\end{array}$ \\
\hline 0 & 83.0 & 16.9 & 0.1 \\
300 & 99.1 & 0.8 & 0.1 \\
500 & 99.3 & 0.5 & 0.2 \\
700 & 99.4 & 0.3 & 0.3 \\
\hline
\end{tabular}

Further investigation of the crust structure indicates that the pore walls are formed by the fusion of the grains which subsequently became hollow during heat treatment as seen in Figure 14(d). From Figure 14(d), it can also be observed that the pore walls (which can be described as capillaric) are also porous similar to those observed for the inner core structure.

EDX analysis of the crust shows that, within the crust, phosphorous level is very low and the surface of the crust is oxidized which explains the formation of hollow walls within the crust. The results are shown in Table 2.

3.7. Inner Structure of Monoliths. The inner structures of the monoliths are examined by using SEM and they are illustrated 


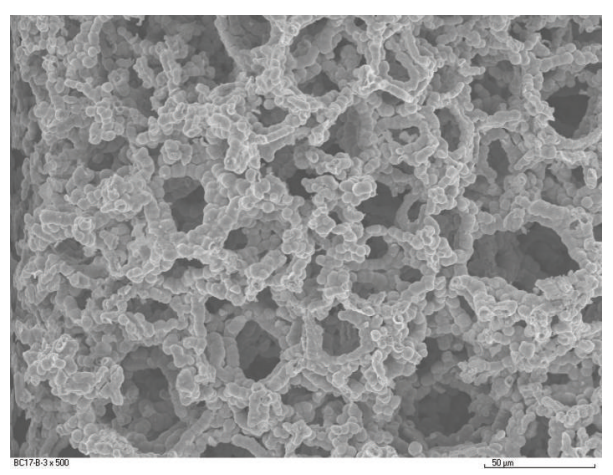

(a)

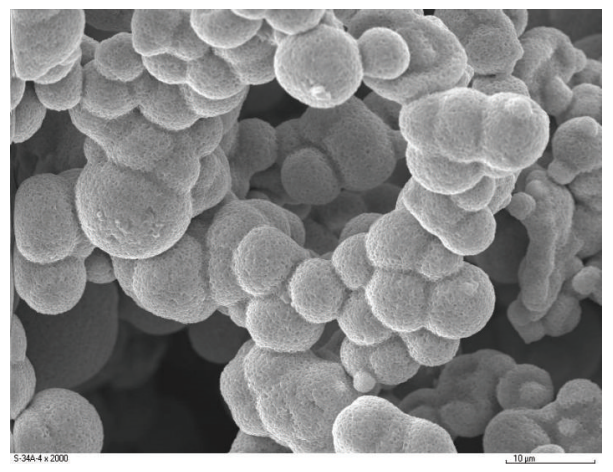

(c)

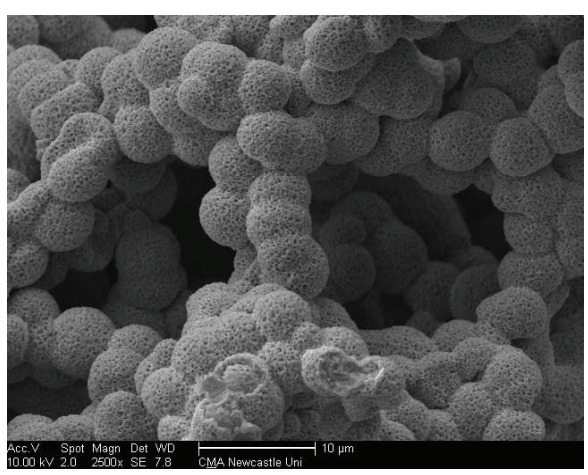

(b)

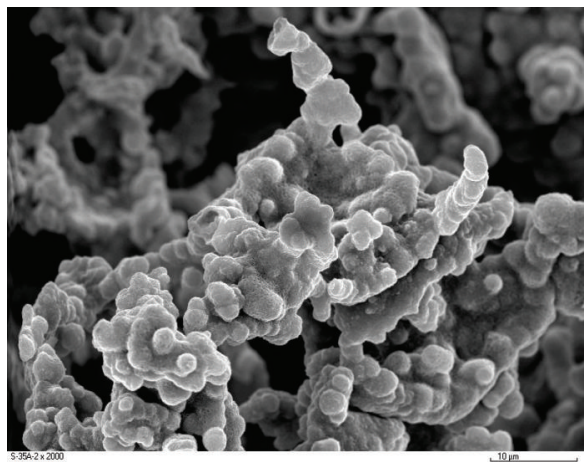

(d)

FIGURE 15: Inner bulk structures of the monoliths showing the effect of reducing agent concentration. Experimental conditions: [Ni] = $0.13 \mathrm{M}$; $T=600^{\circ} \mathrm{C}, H_{r}=10^{\circ} \mathrm{C} / \mathrm{min} ; t_{a}=60 \mathrm{~min}$ followed by cooling in air. (a) General appearance of the bulk structure showing the presence of pore hierarchy with large arterial pores (interconnects/windows) with size range 10-30 $\mu \mathrm{m}$ and pore walls made from the porous capillaric structures of ca. $10 \mu \mathrm{m}$ size. Reducing agent concentration $[\mathrm{P}]=0.63 \mathrm{M}$, scale bar $=50 \mu \mathrm{m}$. (b) Sample as in Figure 15(a) at larger magnification. Scale bar $=10 \mu \mathrm{m}$. (c) Reducing agent concentration $[\mathrm{P}]=1.26 \mathrm{M}$. Scale bar $=10 \mu \mathrm{m}$. (d) Reducing agent concentration $[\mathrm{P}]=2.52 \mathrm{M}$. Scale bar $=10 \mu \mathrm{m}$.

in Figure 15 which shows the presence of large arterial pores and arterial interconnecting holes/windows (Figures 15(a) and 15(b)). The walls of the arterial pores are made from porous grains. The grain size decreases with increasing reducing agent concentration (compare Figures 15(b), 15(c), and 15(d)). The effect of reducing agent concentration on the pore size of the grains is illustrated in Figures 16(a)-16(c). As seen from these SEM images, when the reducing agent concentration is $[\mathrm{P}]=0.63 \mathrm{M}$ or $1.26 \mathrm{M}$, grain surface porosity is similar but when $[\mathrm{P}]=2.52 \mathrm{M}$, the grain surface porosity is smaller but less well defined.

3.8. Overall Chemical Structure of Crust and Bulk. The chemical composition of the crust and the bulk were evaluated by XRD studies. In the first instance, the crust and the bulk of the monoliths were separated out and each part was subjected to XRD analysis. These results are shown in Figure 17 which indicates that $\mathrm{Ni}, \mathrm{NiO}$, and $\mathrm{Ni}_{3} \mathrm{P}$ are present in both the inner structure and crust but $\mathrm{Ni}_{2} \mathrm{P}$ and $\mathrm{Ni}_{12} \mathrm{P}_{5}$ are only present in the inner structure. See Figure 11 for the identification of the XRD peaks.

3.9. Surface Area and Porosity. The surface area of the crust and the internal structure of the monoliths were measured using BET surface area analysis. After measuring the density of the these two parts (crust and bulk) of the monoliths, the specific surface area was calculated. Mercury intrusion technique was used to calculate the porosity. The results of the mercury intrusion technique for the inner structure and crust are shown in Figures 18(a) and 18(b), respectively.

Figure 18 indicates that the porosity of the crust was $63.5 \%$ while the inner bulk structure had a porosity of $75.6 \%$. From Figure 18, it can be seen that both the crust and the bulk of the monolith have bimodal pore size distribution. The arterial pores in the range $5-30 \mu \mathrm{m}$ are in a majority while the second set of pores were in the range of $2-6 \mathrm{~nm}$. Nanopores were more dominant in the bulk of the monolith. These results were further validated by measuring the BET surface area which also provides the range of pore sizes. The surface area of the crust and bulk of the monoliths described in Figure 18 and Table 3 were $0.238 \mathrm{~m}^{2} / \mathrm{g}$ and $0.626 \mathrm{~m}^{2} / \mathrm{g}$, respectively. The pore size distribution obtained by BET surface area analysis was confined to the range of 2 to $160 \mathrm{~nm}$ (Table 3). Within this range, $17.7 \%$ of all the pores were between 2 to $6 \mathrm{~nm}$, which verified the peak in Figure 18(b), obtained by the mercury porosimeter. These results for the crust and the bulk are shown in Table 3 . 


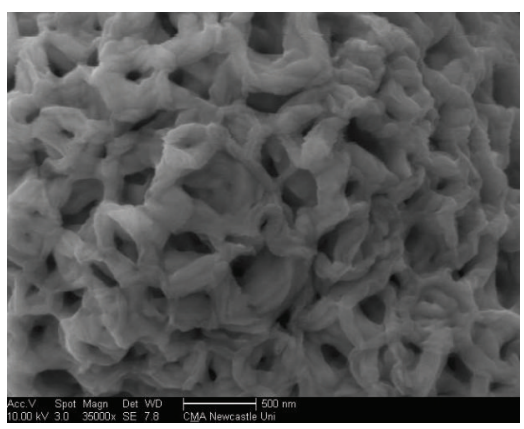

(a)

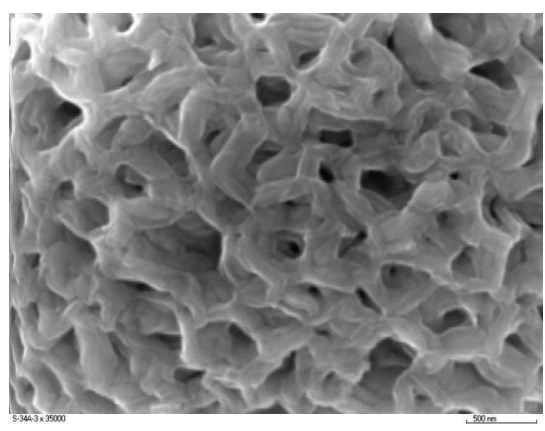

(b)

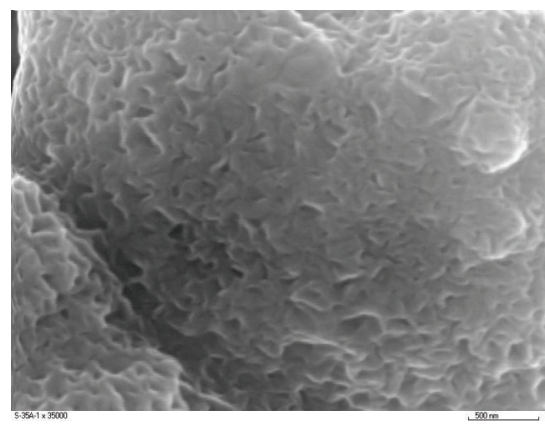

(c)

FiguRE 16: Effect of reducing agent concentration on the surface pore structure of the arterial walls (in the form of porous undulating interconnecting capillaries). Experimental conditions: $[\mathrm{Ni}]=0.13 \mathrm{M} ; \mathrm{T}=600^{\circ} \mathrm{C}, H_{r}=10^{\circ} \mathrm{C} / \mathrm{min} ; t_{a}=60$ min followed by cooling in air. Scale bar $=500 \mathrm{~nm}$. (a) Reducing agent concentration, $[\mathrm{P}]=0.63 \mathrm{M}$. (b) Reducing agent concentration, $[\mathrm{P}]=1.26 \mathrm{M}$. (c) Reducing agent concentration, $[\mathrm{P}]=2.52 \mathrm{M}$.

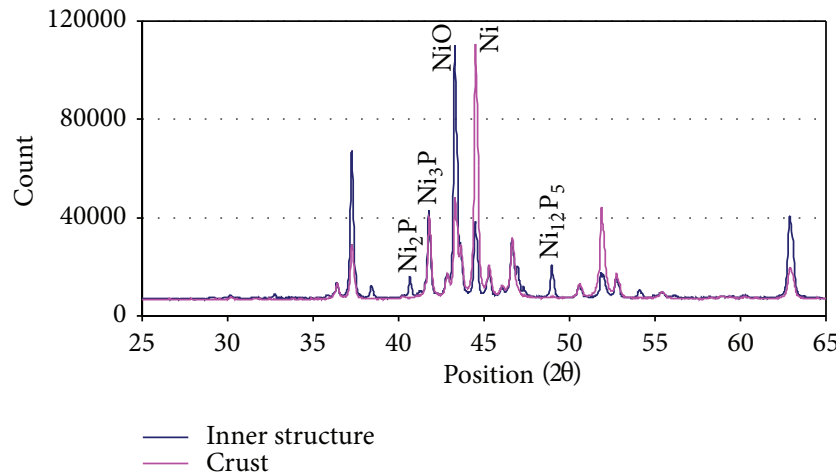

FIGURE 17: Superimposed XRD patterns of the crust and the inner bulk structure of the monolith. Processing conditions: $[\mathrm{Ni}]=0.63 \mathrm{M}$; $[\mathrm{P}]=1.26 \mathrm{M} ; \mathrm{T}=600^{\circ} \mathrm{C}, H_{r}=10^{\circ} \mathrm{C} / \mathrm{min} ; t_{a}=60 \mathrm{~min}$ followed by cooling in air. $\mathrm{Ni}, \mathrm{NiO}$, and $\mathrm{Ni}_{3} \mathrm{P}$ are present in both the crust and inner structure while $\mathrm{Ni}_{2} \mathrm{P}$ and $\mathrm{Ni}_{12} \mathrm{P}_{5}$ are only present in the inner structure.

\section{Conclusions}

Unlike the previous attempts to produce strong microporous monolithic metal foams from PolyHIPE Polymer template, a simple metal deposition solution was successfully used in a flow-enhanced deposition process which resulted in grain formation and faster deposition. The important element of this technique is the electroless deposition under flow while preventing deposition outside the template. This is achieved by the cyclic charge of deposition solution and washing solution, coupled with the reversal of the flow direction to obtain uniform distribution of metal deposition. The effects of flow can be summarized as follows:

(a) Flow removes hydrogen generated during electroless deposition. Failure to remove hydrogen stops electroless deposition.

(b) The deposition template is heated locally to accelerate the electroless deposition. However, the deposition
TAble 3: Pore size distribution by surface area analysis. Processing conditions: $[\mathrm{Ni}]=0.63 \mathrm{M} ;[\mathrm{P}]=1.26 \mathrm{M}, T=600^{\circ} \mathrm{C}, H_{r}=10^{\circ} \mathrm{C} / \mathrm{min}$ $t_{a}=60 \mathrm{~min}$ followed by cooling in air.

\begin{tabular}{lcc}
\hline $\begin{array}{l}\text { Pore diameter range } \\
(\mathrm{nm})\end{array}$ & $\begin{array}{c}\text { Crust } \\
(\%)\end{array}$ & $\begin{array}{c}\text { Inner structure } \\
(\%)\end{array}$ \\
\hline 2 to 6 & 10.9 & 17.7 \\
6 to 8 & 5.4 & 9.1 \\
8 to 10 & 3.1 & 5.0 \\
10 to 12 & 3.7 & 5.6 \\
12 to 16 & 4.3 & 6.2 \\
16 to 20 & 5.1 & 6.2 \\
20 to 80 & 40.3 & 30.2 \\
80 to 160 & 27.2 & 20.0 \\
\hline
\end{tabular}

solution is charged into the template at room temperature to prevent premature deposition in the flow path.

(c) After deposition for a certain length of time, deionized water at high temperature $\left(97^{\circ} \mathrm{C}\right)$ was passed through the deposition template in order to remove reduction products from the electroless deposition as well as heating the deposition template which is also heated externally to prevent heat losses.

(d) As the deposition proceeds, the deposition cycle time can be increased due to the increase in the heat capacity of the monolith which allows faster deposition.

(e) Combination of washing and heating at $90^{\circ} \mathrm{C}$ allows the removal of reaction products such as sodium chloride, thus removing such impurities from the final monolith.

(f) Depending on the metal and reducing agent source, a dense layer is also formed on both sides of the monolith.

Metal deposition from $\mathrm{NiCl}_{2}$ solution with $\mathrm{NaH}_{2} \mathrm{PO}_{2}$ as the reducing agent takes place in the form of grains. Depending 


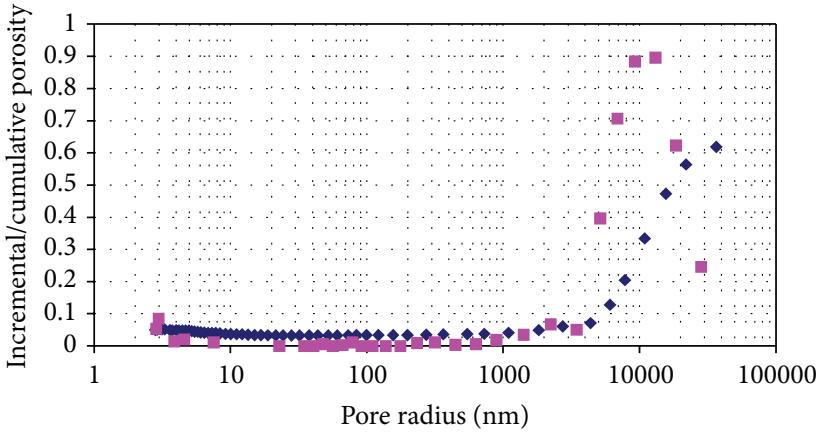

- Cumulative porosity

- Incremental pore radius

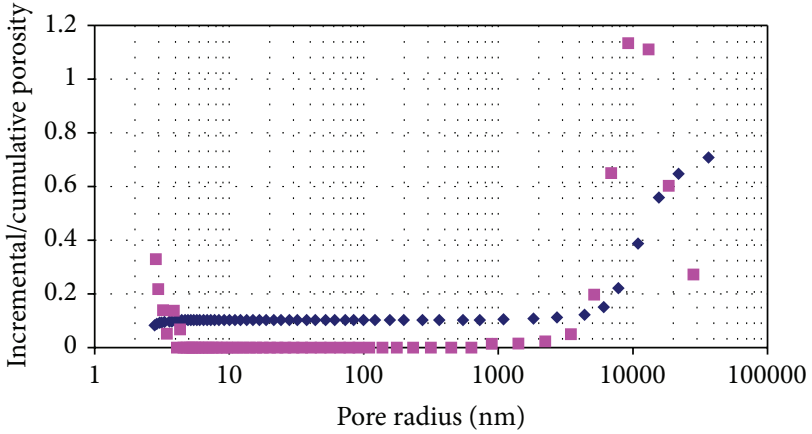

- Cumulative porosity

- Incremental pore radius

(a)

(b)

FIGURE 18: Variation of the cumulative and incremental pore radius with pore size of the crust and bulk. Processing conditions: [Ni] = $0.63 \mathrm{M}$; $[\mathrm{P}]=1.26 \mathrm{M} ; \mathrm{T}=600^{\circ} \mathrm{C}, H_{r}=10^{\circ} \mathrm{C} / \mathrm{min} ; t_{a}=60 \mathrm{~min}$ followed by cooling in air. (a) Crust. (b) Bulk of the monolith.

on the composition of the metal deposition solution and the type of the reducing agent, metal grain size ranges from ca. $20 \mu \mathrm{m}$ to $0.2 \mu \mathrm{m}$. These grains also form the walls of the large arterial pores. During heat treatment, these discrete grains undergo a solid state chemical reaction which results in the following:

(a) Formation of a porous metallic Ni skin covers the unreacted inner core which contains mainly $\mathrm{NiO}$ and $\mathrm{Ni}_{x} \mathrm{P}_{y}$ compounds.

(b) These grains also undergo sintering, thus forming a continuous porous capillary-like (capillaric) structure constituting the walls of the arterial pores.

(c) With further increase in the heat treatment, the solid state reaction continues and the inner structure of the capillaric walls becomes void thus increasing the overall porosity of the monoliths.

(d) The dense layers on the surfaces of the monolith are transformed into a strong metal crust with reduced porosity compared with the bulk of the monolith which is sandwiched between the crusts. The pores of the crust have the same capillaric walls except the size of the arterial pores which are now reduced and the thickness of the walls is increased.

These structures are also encountered in the human body where capillary-like conduits are formed. In the present case, the monoliths have a hierarchy of pores. Convective mass transfer is provided by the arterial pores which have porous capillaric walls, providing catalytic sites for reactions where the diffusional resistance to mass transfer is significantly reduced due to the presence of mesoscale pores between the convective and conductive mass transfer regions.

The mechanisms of electroless metal deposition and subsequent structure development during heat treatment are evaluated. The chemical and physical structures of the monoliths were evaluated. The formation of a strong top surface with reduced porosity (crust) in the monoliths can be desirable as it imparts mechanical strength as well as providing a self-filtering system in gaseous reactions due to the formation of a reduced porosity. The pore volumes of the crust and the bulk are large, $63.5 \%$ and $75.6 \%$, respectively.

\section{Conflict of Interests}

The authors declare that there is no conflict of interests regarding this publication.

\section{Acknowledgments}

The authors acknowledge with thanks that this research was initially supported by Engineering and Physical Sciences Research Council (EPSRC) and Department of Trade and Industry of the UK (Grant no. GR/R59212) through a LINK project with additional grant provided by Intensified Technologies Incorporated (ITI) Ltd. through a Ph.D. support to Dr. Burak Calkan. Further research was funded by an EU FP7 Project (COPIRIDE CP-IP 228853-2), carried out at Newcastle University directed by Prof. G. Akay.

\section{References}

[1] M. T. Kreutzer, F. Kapteijn, J. A. Moulijn, and J. J. Heiszwolf, "Multiphase monolith reactors: chemical reaction engineering of segmented flow in microchannels," Chemical Engineering Science, vol. 60, no. 22, pp. 5895-5916, 2005.

[2] J. Gascon, J. R. van Ommen, J. A. Moulijn, and F. Kapteijn, "Structuring catalyst and reactor-an inviting avenue to process intensification," Catal. Sci. Technol., vol. 5, no. 2, pp. 807-817, 2015.

[3] A. G. Gil, Z. Wu, D. Chadwick, and K. Li, "Micro-structured catalytic hollow fiber reactor for methane steam reforming," Industrial and Engineering Chemistry and Research, vol. 54, no. 21, pp. 5563-5571, 2015. 
[4] M.-O. Coppens, J. Sun, and T. Maschmeyer, "Synthesis of hierarchical porous silicas with a controlled pore size distribution at various length scales," Catalysis Today, vol. 69, no. 1-4, pp. 331-335, 2001.

[5] M.-O. Coppens, "A nature-inspired approach to reactor and catalysis engineering," Current Opinion in Chemical Engineering, vol. 1, no. 3, pp. 281-289, 2012.

[6] G. Akay, "Bioprocess and chemical process intensification," in Encyclopaedia of Chemicals Processing, S. Lee, Ed., vol. 1, pp. 183199, Taylor \& Francis, New York, NY, USA, 2006.

[7] G. J. Davies and S. Zhen, "Metallic foams: their production, properties and applications," Journal of Materials Science, vol. 18, no. 7, pp. 1899-1911, 1983.

[8] J. Banhart, "Manufacture, characterisation and application of cellular metals and metal foams," Progress in Materials Science, vol. 46, no. 6, pp. 559-632, 2001.

[9] L.-P. Lefebvre, J. Banhart, and D. C. Dunand, "Porous metals and metallic foams: current status and recent developments," Advanced Engineering Materials, vol. 10, no. 9, pp. 775-787, 2008.

[10] X. Badiche, S. Forest, T. Guibert et al., "Mechanical properties and non-homogeneous deformation of open-cell nickel foams: application of the mechanics of cellular solids and of porous materials," Materials Science and Engineering A, vol. 289, no. 1-2, pp. 276-288, 2000.

[11] Recemet International, Standard Specification, Recemet International, 2009.

[12] G. Akay, "Flow induced phase inversion in powder structuring by polymers," in Polymer Powder Technology, M. Narkis and N. Rosenzweig, Eds., pp. 542-587, Wiley, New York, NY, USA, 1995.

[13] G. Akay, "Flow-induced phase inversion in the intensive processing of concentrated emulsions," Chemical Engineering Science, vol. 53, no. 2, pp. 203-223, 1998.

[14] M. S. Silverstein and N. R. Cameron, Encyclopaedia of Polymer Science and Technology, Wiley, New York, NY, USA, 2010.

[15] G. Akay, B. Calkan, H. Hasan, and R. Mohamed, "Preparation of nano-structured microporous composite foams," European Patent 2342272, 2013.

[16] G. Akay, M. A. Birch, and M. A. Bokhari, "Microcellular polyHIPE polymer supports osteoblast growth and bone formation in vitro," Biomaterials, vol. 25, no. 18, pp. 3991-4000, 2004.

[17] E. Erhan, E. Yer, G. Akay, B. Keskinler, and D. Keskinler, "Phenol degradation in a fixed-bed bioreactor using microcellular polymer-immobilized Pseudomonas syringae," Journal ofChemical Technology and Biotechnology, vol. 79, no. 2, pp. 195206, 2004.

[18] G. Akay, E. Erhan, and B. Keskinler, "Bioprocess intensification in flow-through monolithic microbioreactors with immobilized bacteria," Biotechnology and Bioengineering, vol. 90, no. 2, pp. 180-190, 2005.

[19] G. Akay and D. R. Burke, "Agro-process intensification through synthetic rhizosphere media for nitrogen fixation and yield enhancement in plants," American Journal of Agricultural and Biological Science, vol. 7, no. 2, pp. 150-172, 2012.

[20] G. Akay and S. Fleming, "Agro-process intensification: soilborne micro-bioreactors with nitrogen fixing bacterium Azospirillum brasilense as self-sustaining biofertiliser source for enhanced nitrogen uptake by plants," Green Processing and Synthesis, vol. 1, no. 5, pp. 227-237, 2012.

[21] G. Akay, T. Pekdemir, A. M. Shakorfow, and J. Vickers, "Intensified demulsification and separation of thermal oxide reprocessing interfacial crud (THORP-IFC) simulants," Green Processing and Synthesis, vol. 1, no. 1, pp. 109-127, 2012.

[22] N. Barlık, B. Keskinler, M. M. Kocakerim, and G. Akay, "Surface modification of monolithic PolyHIPE Polymers for anionic functionality and their ion exchange behavior," Journal of Applied Polymer Science, vol. 132, no. 29, 2015.

[23] G. Akay, C. A. Jordan, and A. H. Mohamed, "Syngas cleaning with nano-structured micro-porous ion exchange polymers in biomass gasification using a novel downdraft gasifier," Journal of Energy Chemistry, vol. 22, no. 3, pp. 426-435, 2013.

[24] A. Brenner and G. Riddell, United States Patent No. 2532283, 1950.

[25] S. S. Djokic, "Electroless deposition of metals and alloys," Modern Aspects of Electrochemistry, vol. 35, pp. 51-133, 2002.

[26] G. O. Mallory, "Influence of the electroless plating bath on the corrosion resistance of the deposits," Plating, vol. 61, no. 11, p. 1005, 1974.

[27] W. D. Fields, R. N. Duncan, and J. R. Zickgraf, "Electroless nickel plating," in Metals Handbook, Volume 5-Surface Cleaning, Finishing and Coating, ASM Handbook Committee, Metals Park, Ohio, USA, 1982.

[28] S. Sotiropoulos, I. J. Brown, G. Akay, and E. Lester, "Nickel incorporation into a hollow fibre microporous polymer: a preparation route for novel high surface area nickel structures," Materials Letters, vol. 35, no. 5-6, pp. 383-391, 1998.

[29] V. Kröger, M. Hietikko, D. Angove et al., "Effect of phosphorus poisoning on catalytic activity of diesel exhaust gas catalyst components containing oxide and Pt," Topics in Catalysis, vol. 42-43, no. 1-4, pp. 409-413, 2007.

[30] W.-J. Wang, H.-X. Li, and J.-F. Deng, "Boron role on sulfur resistance of amorphous $\mathrm{NiB} / \mathrm{SiO}_{2}$ catalyst poisoned by carbon disulfide in cyclopentadiene hydrogenation," Applied Catalysis A: General, vol. 203, no. 2, pp. 293-300, 2000.

[31] G. Akay, M. Dogru, B. Calkan, and O. F. Calkan, "Flow induced phase inversion phenomenon in process intensification and micro-reactor technology," in Microreaction Technology and Process Intensification, Y. Wang and J. Halladay, Eds., chapter 18, pp. 286-308, American Chemical Society, New York, NY, USA, 2005.

[32] Y. Kubota, H. K. Kleinman, G. R. Martin, and T. J. Lawley, "Role of laminin and basement membrane in the morphological differentiation of human endothelial cells into capillary-like structures," The Journal of Cell Biology, vol. 107, no. 4, pp. 1589$1598,1988$.

[33] D. C. Darland and P. A. D'amore, “TGF $\beta$ is required for the formation of capillary-like structures in three-dimensional cocultures of 10T1/2 and endothelial cells," Angiogenesis, vol. 4, no. 1, pp. 11-20, 2001.

[34] A. Atkinson and D. W. Smart, “Transport of nickel and oxygen during the oxidation of nickel and dilute nickel/chromium alloy," Journal of the Electrochemical Society, vol. 135, no. 11, pp. 2886-2893, 1988.

[35] A. W. Harris and A. Atkinson, "Oxygen transport in growing nickel oxide scales at $600-800^{\circ} \mathrm{C}$," Oxidation of Metals, vol. 34, no. 3-4, pp. 229-258, 1990. 
[36] H. Kyung and C. K. Kim, "Microstructural evolution of duplex grain structure and interpretation of the mechanism for $\mathrm{NiO}$ scales grown on pure Niand Cr-doped substrates during high temperature oxidation," Materials Science and Engineering B: Solid-State Materials for Advanced Technology, vol. 76, no. 3, pp. 173-183, 2000.

[37] S. Chevalier, F. Desserrey, and J. P. Larpin, "Oxygen transport during the high temperature oxidation of pure nickel," Oxidation of Metals, vol. 64, no. 3-4, pp. 219-234, 2005. 

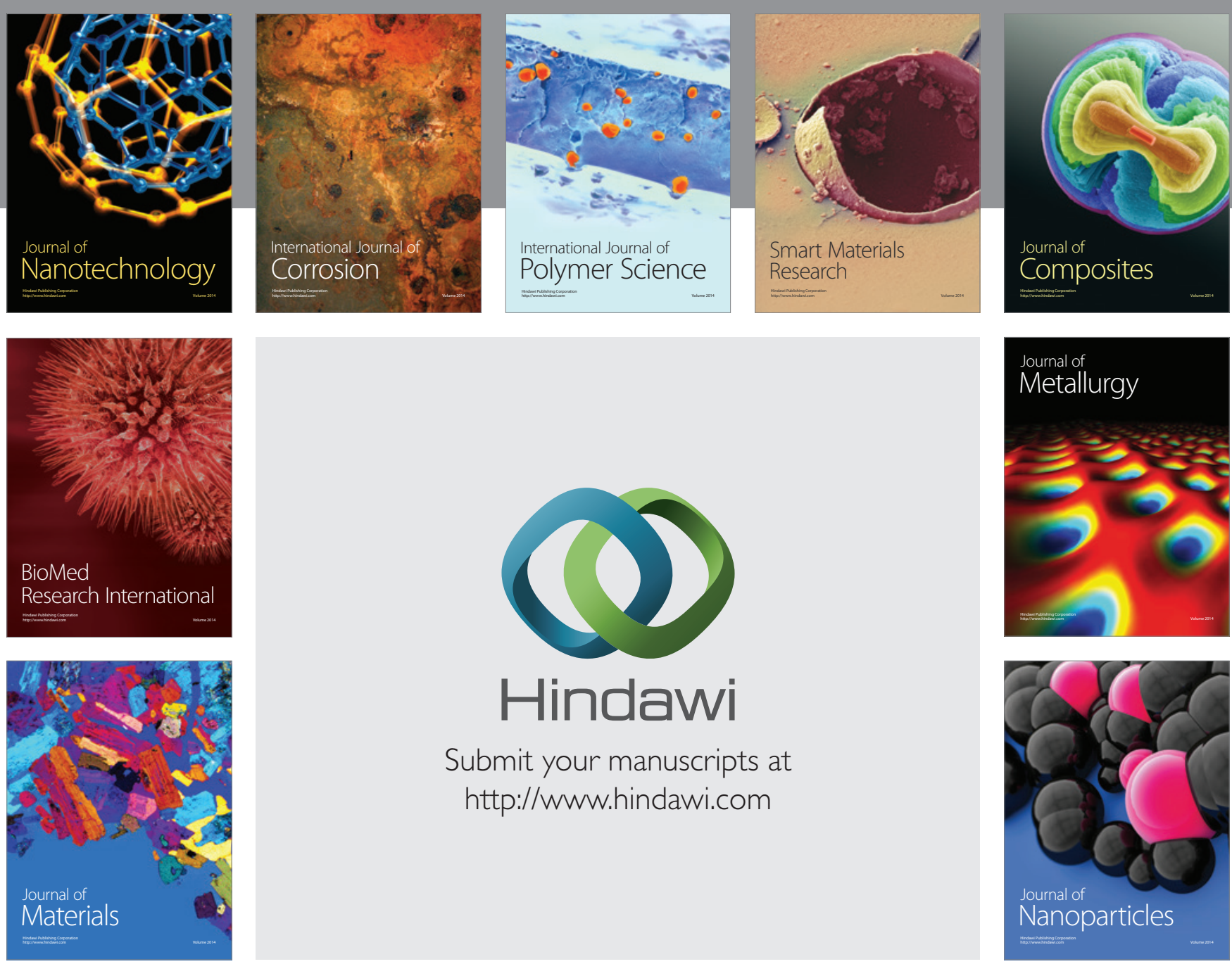

Submit your manuscripts at http://www.hindawi.com
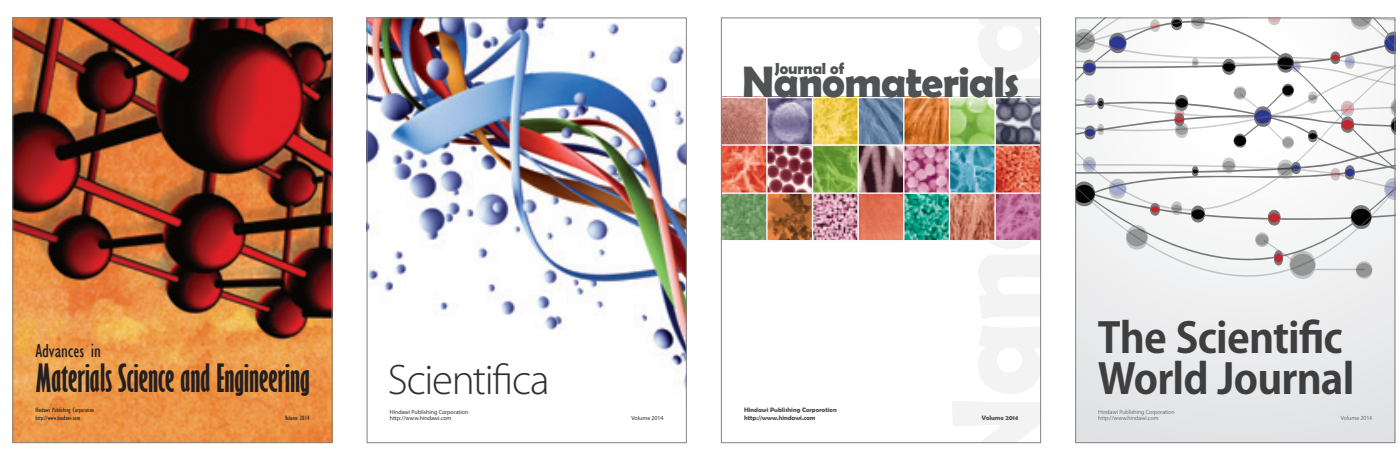

\section{The Scientific World Journal}
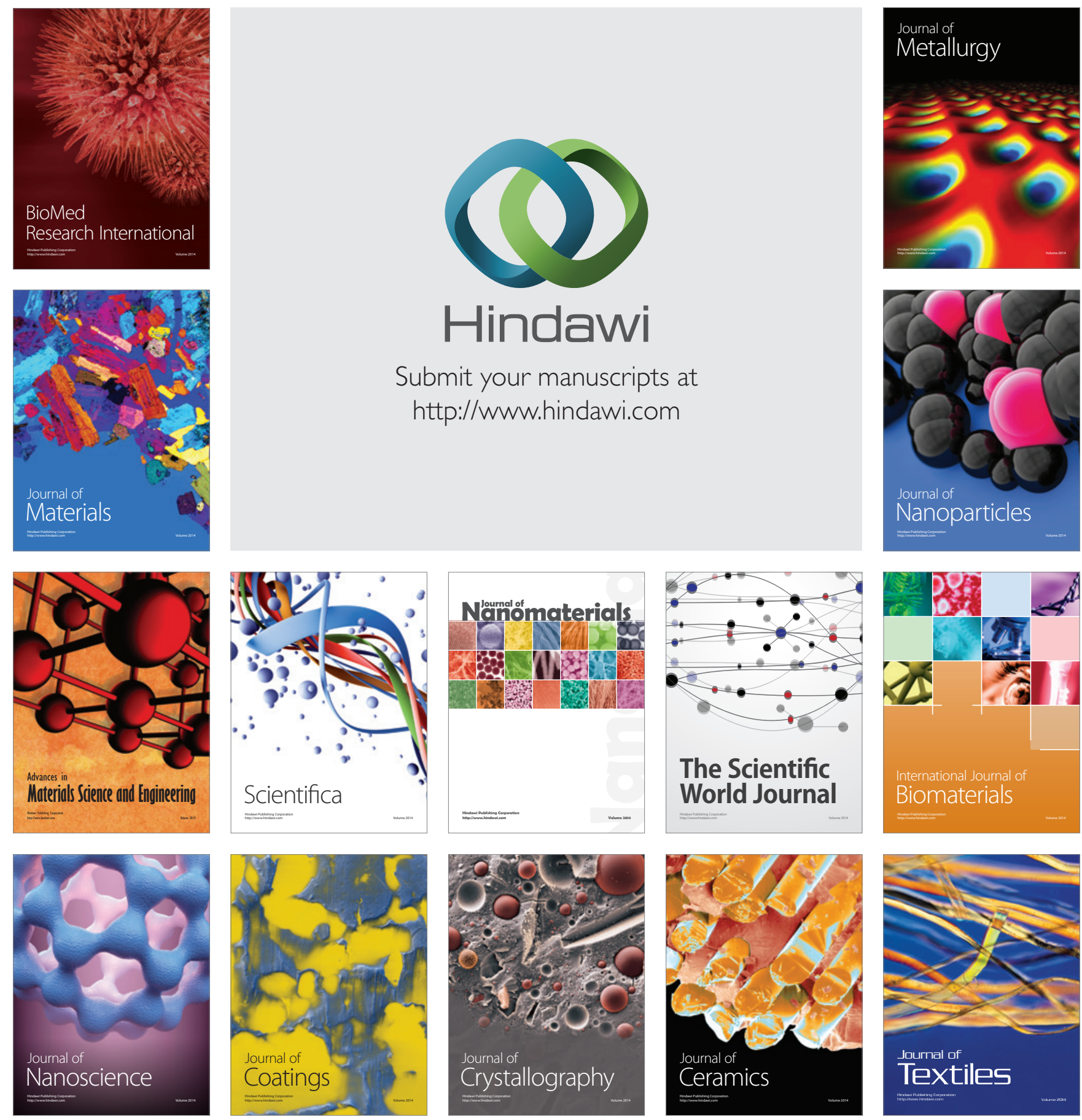